\title{
The Costs and Benefits of Regional Cooperation on Grain Reserves: The Case of ECOWAS
}

\author{
Lukas Kornher and Matthias Kalkuhl
}

\subsection{Introduction}

Despite widespread skepticism towards public intervention in food markets, many governments in sub-Saharan Africa and elsewhere in the world responded to the 2007/2008 global food crisis by implementing or enhancing public stockholding. These interventions are criticized due to their distortive effects on private trading and their high operating costs (Newbery and Stiglitz 1981; Miranda and Helmberger 1988; Tschirley and Jayne 2010). On the other hand, the crisis also showed that international trade is incapable of dampening supply and price shocks when exporters insulate their domestic markets from the international price development (Martin and Anderson 2012; Porteous 2012).

Child mortality and general food insecurity in West Africa are among the highest in the world (FAO et al. 2013; von Grebmer et al. 2013). The region is a major rice importer and is dependent on these imports to meet food consumption targets. International food aid has been an important factor in offsetting fluctuations in national production but has been decreasing rapidly since the middle of the last decade (FAOSTAT 2014). For these reasons, the Economic Community of West African States (ECOWAS) community decided to make plans for a regional emergency reserve. ${ }^{1}$

\footnotetext{
${ }^{1}$ For a detailed description of the current proposal, see ECOWAS Commission et al. (2012).

L. Kornher $(\bowtie)$

University of Kiel, Kiel, Germany

e-mail: 1kornher@food-econ.uni-kiel.de

M. Kalkuhl

Center for Development Research, University of Bonn, Bonn, Germany
} 
Regional food reserves are viable and comparably cheap means, as an alternative to national reserves (FAO et al. 2011; Wright and Cafiero 2011). This is not a new idea. International risk sharing and multinational insurance schemes were heavily discussed in the 1970s (Johnson 1976; Reutlinger et al. 1976; Konandreas et al. 1978). As with the concept of any insurance, pooling national supplies stabilizes regional food availability due to the imperfect correlation of national production shocks (Koester 1986). However, potential benefits of cooperation can only be realized when countries agree on common rules under which the reserve operates. In other words, how much each country contributes and under which circumstances releases from the reserve are authorized. This requires that all countries benefit from cooperation vis-à-vis without cooperation.

Academic literature on regional storage cooperation is scant. Existing studies underline the potential of risk sharing without explicitly conceptualizing the link to storage. This study aims at closing the gap by providing a methodology to evaluate potential benefits of regional storage cooperation. The main objective is to examine whether storage cooperation could enhance food security in West Africa. Specifically, various possible storage policies are tested, and an efficient load distribution among participating countries is discussed. Generally, the methodology is applicable to any group of countries and not limited to West Africa.

The remainder of the chapter is structured as follows. First, Sect. 15.2 discusses food security and storage as well as trade as means to increase food availability and introduces the concept of regional cooperation. Then, Sect. 15.3 and Sect. 15.4 outline the framework for assessing the benefits of cooperation and then define optimal levels of storage in the presence of stochastic supply with the goal of stabilizing national consumption. The results of this study, including sensitivity analysis, are presented in Sect. 15.5. Section 15.6 concludes this chapter and discusses policy implications.

\subsection{Food Reserves, Trade, and Benefits of Regional Cooperation}

Annual production is subject to great fluctuation and consequently may be insufficient to meet stable consumption needs in non-exporting economies. Food imports and stocks can offset these fluctuations. The empirical literature emphasizes the interchangeability of trade and storage to offset unstable production (Williams and Wright 1991; Makki et al. 1996, 2001). There are good reasons to believe that free market stock levels in many developing countries are not sufficiently high or optimal (Newbery and Stiglitz 1981; Gilbert 2011). Similarly, the potential gains from regional trade are not exhausted in many developing countries (Badiane et al. 2014). Gilbert (2011) suggests considering a country's specific characteristics to determine the right policy. So, exporters can easily regulate domestic food availability by flexible export quantities. Trade is also advantageous if supply shocks between countries are independent or negatively correlated (Koester 1984; Badiane et al. 2014). In contrast, importers and countries that switch between net importer 
and net exporter can successfully insure themselves against high international prices by keeping security stocks. Furthermore, high transportation costs (e.g., for landlocked countries) and/or long periods of shipment make public reserves favorable to trade. Trade can also transmit market instability from partner countries into national markets (Makki et al. 2001). Moreover, relying on imports to manage food availability can be problematic when partner countries are noncooperative and restrict exports at times (Gouel and Jean 2015). This was a frequently observed practice during the price surges in 2007/2008 (Martin and Anderson 2012; Porteous 2012). For these reasons, food reserves have a structural advantage over trade integration, at least from a government's perspective. ${ }^{2}$

Food reserves can be divided into two broad categories: emergency or strategic reserves and buffer stocks. The purpose of the former is to overcome food supply shortfalls caused by weather-related shocks (such as droughts or floods), pests, and political instability (Lynton-Evans 1997). During a crisis, additional food is brought into the system via targeted food subsidies (e.g., food stamps, food for work, school feeding programs, etc.). In contrast, buffer stocks are used to generally stabilize commodity prices at both ends of the distribution. In doing so, public institutions buy and sell commodities in order to increase market supply or demand. The objective of the buffer stock is to keep prices within a price band, between a predetermined floor and ceiling price (Newbery and Stiglitz 1981). Purchases and sales can be realized not only in the open market but also through contract farming and subsidized sales to public and private entities. The main danger lies in having to operate buffer stocks permanently, which implies permanent market intervention. Notably, intervention levels of existing national reserves and buffer stocks vary significantly across countries. ${ }^{3}$

The gains from cooperation rest on the concept of risk pooling. Risk pooling, or diversification, originates from the insurance and finance literature and is the central business concept of every insurance company. Pooling uncertain outcomes of multiple individuals reduces the volatility of their joint outcome. Expected losses remain the same, but insurance companies can reduce their accrued liabilities if (and only if) losses of policyholders are not perfectly correlated. On the same account, a group of countries can reduce the stocking norm of their food reserves by sharing the risk of supply shocks. Statistically, the covariance and correlation of individual risks is the key determinant for gains from cooperation. If shocks are idiosyncratic, then risk sharing is feasible. On the contrary, if shocks are highly correlated, the benefits of cooperation will be small (Townsend 1995). From this, it is possible to conclude

\footnotetext{
${ }^{2}$ On the one hand, deepening trade relationships require trading partners to be equally willing to cooperate; on the other hand, trade integration usually takes time to establish business relations and trust between actors.

${ }^{3}$ Agricultural markets in India, Zambia, and Indonesia are dominated by state-owned enterprises that buy, stock, and sell a very large share of marketed grains. In contrast, several countries maintain public stockholding that is unlikely to affect market prices due to its small size. In an ideal world, buffer stocks should be large enough to influence prices but small enough not to crowd out private investment and distort markets.
} 
that supply instability in one region (a group of countries) is lower if national supply quantities are independent or negatively correlated. The potential of regional risk sharing with respect to supply shocks of major food crops in Africa is well acknowledged in existing studies (Koester 1986; Badiane et al. 2014). Since supply variability is the main reason to establish food reserves, lower supply variability implies that a reserve requires lower stock levels.

Wright and Cafiero (2011) also discuss the role of regional reserves in increasing a country's commitment to refrain from imposing export regulations in times of a food crisis. These commitments seem unfeasible under the common WTO discipline. At the same time, governments dispose of ways to impede exportation through the over-bureaucratization of legal processes. Hence, it is conceivable to combine storage and trade cooperation. In doing so, participating countries provide a share of their national supply for exporting (if harvests are sufficiently high) and in return receive the entitlement to release stocks during a crisis.

A multinational reserve involving a buffer stock scheme, with market purchase and release, seems very challenging to realize. If the regional reserve operates separately at national levels, trade between countries would undermine the principles of operation and could lead to complete inefficacy. On the contrary, if the region is considered as a single market, intervention prices are extremely difficult to determine since price levels naturally differ among member countries, especially without a common currency. Therefore, strategic humanitarian reserves should be preferred.

\subsection{Assessment of the Costs and Benefits of Cooperation}

In order to assess the costs and benefits of regional cooperation, we compare consumption variability and reserve levels under regional cooperation vis-à-vis without cooperation. In other words, optimal stocking norms are defined for each individual country and for specific groups of countries. If a country's welfare is given by:

$$
U=H[\operatorname{VAR}(C(\alpha))]-G(\alpha)
$$

where $H$ is a function decreasing with consumption variability $\operatorname{Var}(C)$ and $G$, the costs of interventions that increase with the stock-to-use ratio $\alpha ; \alpha \in(0,1)$ reduces consumption variability and thus increases $H$ in the following manner: $H^{\prime}(\alpha)>0$ and $H^{\prime \prime}(\alpha)<0$.

Then welfare increases with consumption stability and decreases with higher reserve stock levels. A government chooses the optimal policy by opting for a stock-to-use ratio $(\alpha)$ that maximizes social welfare. Accordingly, there is a tradeoff when increasing the stock level of the reserve. Higher stock levels guarantee greater consumption stability but are associated with higher operational costs. 
The optimal $\alpha$ maximizes social welfare without cooperation. On the contrary, in the case of regional storage cooperation, the level of consumption variability, and thus the optimal stock-to-use ratio, is no longer determined by an individual country through welfare optimization but by a common decision among all member countries. Heterogeneity among regional partners could explain why they may disagree about common regional policies. For instance, countries with high supply instability may be satisfied with a relatively moderate level of consumption stability, whereas countries with stable national supply need regional consumption stability to be sufficiently high to benefit from an intervention. In regional integration, states voluntarily hand their decision-making power over to supernational entities and create a political power that overrules national policies (Heinonen 2006). Taking a game-theoretic approach, the median voter will decide on the level of consumption stability in such a setting (Alesina et al. 2005). As a consequence, countries with similar economic structures lose less in comparison with countries with divergent economic structures.

Thus, the benefits of regional risk sharing are evaluated against the costs of a potentially suboptimal choice of stock-to-use ratio. Following the framework mentioned above, the net benefits $\left(X_{i}\right)$ of cooperation for each country $i$ are given by the difference in social welfare before and after joining the regional agreement:

$$
N_{i}=H_{i}\left[\operatorname{VAR}\left(\widehat{C}_{i}\right)\right]-H_{i}\left[\operatorname{VAR}\left(C_{i}^{*}\right)\right]+G_{i}\left(\alpha_{i}^{*}\right)-G_{i}\left(\widehat{\alpha}_{i}\right)
$$

where $\operatorname{VAR}\left(C_{i}^{*}\right)$ is the consumption variability resulting from the optimal $\alpha_{i}^{*}$ for an individual country without cooperation or the optimal level of target consumption chosen by the country. Analogously, $\operatorname{VAR}\left(\widehat{C}_{i}\right)$ is the consumption variability under cooperation determined by $\widehat{\alpha}$, which is jointly selected by the member countries.

However, without specifying the functions $H_{i}$ and $G_{i}$, welfare impacts are not unambiguously appraisable. Definite predictions are possible when benefits increase and costs decrease and vice versa. Yet in the remaining cases, a specific functional form of $H_{i}$ and $G_{i}$ is required for a clear assessment.

The framework introduced requires the definition of optimal stocking rules or stock-to-use ratios that are applied by each country. This implies stocks need to be sufficiently high to permit stock releases that achieve the desired level of consumption (stability). At the same, the policy governing the release of stocks from the reserve must be strictly defined. Within regional storage cooperation, the member countries must contribute to the endowment of the regional reserve. These contributions could be proportionally equal. In this case, all countries would have identical stock-to-use ratios. Alternatively, Koester (1986) proposes that a country should contribute according to its individual stock needs. In doing so, countries with greater supply instability would be asked to contribute more than countries with greater supply stability. In this way, all countries would benefit from the cooperation in the same manner. Again, the releases from the reserve must make sure that the desired consumption (stability) is given for each member country. This means that whenever a country's supply falls short of its target level (specified in the 
rules of the reserve), the country would receive stocks from the regional reserve to guarantee national consumption. As opposed to this, if a country's domestic supply is sufficient in satisfying domestic demand in a particular year, then the country does not receive anything from the regional reserve.

\subsection{Optimal Stocks and Stocking Rule}

In this analysis, two possible types of reserve are considered: an emergency reserve, which releases stocks whenever supply falls short of a predetermined level, and a buffer stock regime, which stabilizes supply in both directions.

\subsubsection{Emergency Reserve}

In line with the existing literature, the optimal reserve level should be able to absorb historical production and supply shocks by a predetermined probability or margin (Johnson 1976; Konandreas et al. 1978; Koester 1986). Let the market identity be given by:

$$
C_{t}=Q_{t}+\mathrm{IM}_{t}-\mathrm{EX}_{t}=X_{t}
$$

where total consumption $\left(C_{t}\right)$ equals production $\left(Q_{t}\right)$ plus imports $\left(\mathrm{IM}_{t}\right)$ minus exports $\left(\mathrm{EX}_{t}\right)$. Imports and exports are assumed to be from international markets only. National production and imports constitute total national supply $\left(X_{t}\right)$.

In case production falls short of the desired level, minimum consumption of a country can be satisfied through additional imports. However, food availability has generally (not only in the case of West Africa) seen drastic variations from year to year despite food imports. Furthermore, international food prices fluctuate and therefore make the food import bill unpredictable (Sarris et al. 2011). In such a situation, the emergency reserve would step in to lift consumption to the desired minimum level. Following Konandreas et al. (1978), the desired minimum level is referred to as target consumption level $c^{*}$ (e.g., $95 \%$ of long-term trend). Then, consumption in a given year is given by:

$$
C_{t}=\max \left[X_{t}, c^{*} E\left[C_{t}\right]\right]
$$

where $X_{t}$, is the actual supply in at $t$, and $c^{*} E\left[C_{t}\right]$ is the target consumption based on expected supply that is calculated from historical values. By definition $c^{*} \in[0,1]$.

In words, when national supply is higher than the target level, consumption just equals total supply. But whenever supply is lower than the target level, the reserve releases the necessary amount to close the gap to satisfy at least $c^{*} \times 100 \%$ of the expected consumption. Consumption is expected to always equal supply. In order to satisfy Eq. (15.4), stocks need to compensate for supply shortfalls of more than $(1-c) \times 100 \%$. Subsequently, the ratio of consumption to be stored $(\alpha)$ is defined 
as the ratio between stocks and expected consumption:

$$
\begin{gathered}
S_{t}^{*}=\max _{t}\left[0, c^{*} E\left[X_{t}\right]-\left(X_{t}\right)\right] \text { for } t=t_{1}, \ldots, t_{n} \\
\alpha_{t}^{*}=\frac{S_{t}^{*}}{E\left[C_{t}\right]}
\end{gathered}
$$

where $\max _{t}\left[c^{*} E\left[X_{t}\right]-\left(X_{t}\right)\right]$ is the largest historical supply shortfall over the period $t_{1}-t_{n}$. If supply never falls below $c^{*} E\left[X_{t}\right]$, no stocks shall be carried. $S_{t}^{*}$ are optimal stocks, and $\alpha_{t}^{*}$ is the optimal stock-to-use ratio at present time.

In regional cooperation, the reserve must carry sufficiently large stocks to satisfy the sum of supply shortfalls in all member countries, so that regional consumption is given by

$$
C^{R}{ }_{t}=\sum_{i} C_{i t}
$$

where $C^{R}{ }_{t}$ is the regional consumption, which is the sum of the consumption in each member country given by Eq. 15.4 .

Accordingly, the individual national reserves carry total regional stocks which are the sum of national stocks:

$$
S_{t}^{R}=\sum_{i} S_{i t}^{*}=\sum_{i} \max _{t}\left[0, c^{*}{ }_{i} E\left[X_{i t}\right]-\left(X_{i t}\right)\right] \text { for } t=t_{1}, \ldots, t_{n}
$$

where $S^{R}$ is the amount of regional stocks and all other parameters are described as above.

If national supply shortfalls are not perfectly correlated, then the common regional reserve must carry only enough stocks to balance the sum of the shortfalls that occur in a particular year.

$$
\widehat{S}_{t}^{R}=\max _{t}\left[0, \sum_{i} \widehat{c} E\left[X_{i t}\right]-\left(X_{i t}\right)\right] \text { for } t=t_{1}, \ldots, t_{n}
$$

where $\max _{t}\left[0, \sum_{i} \widehat{c} E\left[X_{i t}\right]-\left(X_{i t}\right)\right]$ is the largest historical regional supply shortfall over the period $t_{1}-t_{n}$.and $\widehat{c}$ is the consumption target in a regional cooperation which does not vary between member countries $i$. If supply never falls below $\widehat{c} E\left[X_{t}\right]$, no stocks shall be carried.

The regional reserve shall be endowed with stocks by contributions from its member countries. In this instance, national stocking norms change to:

$$
\widehat{S_{\mathrm{i} t}}=s_{i} \widehat{S}_{t}^{R}=\widehat{\alpha_{t}} E\left[X_{i t}\right]
$$




$$
\begin{aligned}
& \text { with } \widehat{\alpha}_{t}=\frac{S_{t}^{R}}{E\left[C^{R}{ }_{t}\right]} \\
& \widetilde{S}_{i t}=\frac{S_{i t}}{\sum_{i=1}^{n} S_{i t}} S_{t}^{R}
\end{aligned}
$$

where $s_{i}$ is a country's share of the total regional consumption; $\widehat{S_{i t}}$ and $\widetilde{S}_{i t}$ are a country's contributions to the regional reserve under equal and relative contributions. Under equal contributions, all countries have the same stock-to-use ratio $\widehat{\alpha}$ in $t$. Under relative contributions, $\widehat{\alpha}_{i}$ varies among countries by the extent to which national stocks vary across countries without regional cooperation.

However, regional storage cooperation and intra-regional trade cooperation can work hand in hand. For instance, it is conceivable to assume that supply surpluses are exported to the region. Hence, supply shortfalls in neighboring countries can be first alleviated through trade before releasing stocks from the regional reserve. Storage cooperation could also increase the commitment to such arrangements (Wright and Cafiero 2011).

A reasonable assumption may be that a country's excess surpluses $\mathrm{ES}_{i t}=X_{i t}-$ $E\left[X_{i t}\right]$ are approved for export. Thus, intra-regional trade and regional stocks are given by:

$$
\begin{gathered}
T^{R}{ }_{t}=\sum_{i} \max \left[0, X_{i t}-E\left[X_{i t}\right]\right] \\
S_{t}^{R}=\max _{t}\left[0,\left[\sum_{i} \widehat{c} E\left[X_{i t}\right]-\left(X_{i t}\right)\right]-T^{R}{ }_{t}\right] \text { for } t=t_{1}, \ldots, t_{n}
\end{gathered}
$$

where $T^{R}{ }_{t}$ is the total quantity traded within the region in a particular year, which is computed as the sum of excess surpluses across all member countries. Regional trade reduces the amount of regional stocks, which are necessary to alleviate supply shocks. Therefore, historical shortfalls, which have to be balanced, diminish with growing amount of intra-regional trade. Contributions of member countries and stock-to-use ratios can be computed in a way analogous to the case without intraregional trade.

\subsubsection{Stabilization Reserve}

As opposed to the emergency reserve described in the previous section, the concept of the stabilization reserve is derived from the classical storage literature (Gustafson 1958). Stocks are regarded as part of national supply and demand. Each year, a constant portion $(\gamma)$ of the total available supply is kept as stock in a reserve; this 
is a linear approximation of the stocking rule pioneered by Gustafson. In this way, stock levels change over time. After years with good harvests, stock levels will be become higher (and will correspondingly become lower after bad harvests). In this case, the market identity from Eq. (15.3) above changes to:

$$
\begin{gathered}
C_{t}=\mathrm{X}_{t}-\Delta S_{t} \\
\Delta S_{t}=S_{t+1}-S_{t} \\
S_{t+1}=\gamma\left(S_{t}+X_{t}\right)
\end{gathered}
$$

where all parameters are defined the same as above. $S_{t}$ is opening stocks available for consumption in $t$, and $S_{t+1}$ are the stocks carried to the next period. $\Delta S_{t}$ is the change in ending stocks from $t-1$ to $t . \gamma$ is the constant portion of total available supply that is carried over to the next period.

Inserting Eq. (15.15) in Eq. (15.14), consumption can be written $\mathrm{as}^{4}$ :

$$
\mathrm{C}_{t}=(1-\gamma)\left(X_{t}\right)+(1-\gamma) S_{t}
$$

Since supply naturally fluctuates, we want to know the expected level of stocks. This can be easily derived since $E\left[S_{t}\right]=E\left[S_{t+1}\right]$. Thus,

$$
\begin{aligned}
S_{t}^{*} & =\frac{\gamma E\left[X_{t}\right]}{(1-\gamma)} \\
\alpha^{*} & =\frac{\gamma}{1-\gamma}
\end{aligned}
$$

where $S_{t}^{*}$ is the optimal stock level and $\alpha^{*}$ the corresponding optimal stock-to-use ratio.

The objective of the stabilization reserve is to stabilize consumption. Hence, it is of interest is to investigate how consumption variability depends on the stocking parameter $(\gamma)$. Taking the variance of Eq. (15.18) yields:

$$
\begin{aligned}
& \operatorname{VAR}(C)=\frac{1-\gamma}{1+\gamma} \operatorname{VAR}(X) \\
& \operatorname{CV}(C)=\sqrt{\frac{1-\gamma}{1+\gamma}} \operatorname{CV}(X),
\end{aligned}
$$

${ }^{4}$ For the complete analytical derivation, see Kornher (2015). 
where VAR $(C)$ and VAR $(X)$ are variance of consumption and supply, respectively, and $\mathrm{CV}(C)$ and $\mathrm{CV}(X)$ are the respective coefficients of variation.

Consequently, consumption variability is a function of supply variability and the stocking parameter $(\gamma)$. The larger the supply variability, the larger the consumption variability. On the other hand, increasing $\gamma$ stabilizes consumption. It is important to note that the stabilization reserve in the case of regional storage cooperation works only if markets are fully integrated and if demand and supply adjust perfectly between countries. In this case, regional supply and consumption variability are equal to national supply and consumption variability for each individual member country.

\subsection{Results}

\subsubsection{Supply Patterns in West Africa}

Table 15.1 provides economic and agricultural statistics on West African countries involved in this analysis. Heterogeneity between countries exists with respect to income level and food security status. While Ghana and Cape Verde have relatively low prevalence of hunger and malnutrition, $12 \%$ of the total ECOWAS population is still undernourished, with alarmingly high figures in the Sahel zone. With the exception of Mali and to some extent Burkina Faso, all countries depend on imports to guarantee sufficient supply of grain. In general, it is observed that coastal countries have larger import-to-production ratios, with Cape Verde, Cote d'Ivoire, Liberia, Senegal, and Mauritania having ratios above one. Overall, Nigeria's prominent role in the region is to be noted. Due to the country's population, more than $40 \%$ of regional production originates from Nigeria, and thus the country would likely assume a leading role in any regional cooperation agreement.

The subsequent analysis is based on fluctuations in national food production and supply. Supply is calculated as production plus imports. In this way, extreme fluctuations in the production of many import-dependent countries are extenuated. Therefore, the analysis of supply shocks is considered to be more instructive. All imports are considered to be from international markets. In the analysis which considers intra-regional trade, these international imports are considered to be part of the national supply.

Since production increases with agricultural productivity and population growth, unadjusted measures of variability as variance and coefficient of variation become inappropriate measures of variability (Cuddy and Della Valle 1978). One possibility is to correct coefficient of variation and variance by the fitness of a trend function (Koester 1984). Alternatively, variability can be measured after detrending the time series. Thus, variability in supply is given as the variation around a trend. A linear 
Table 15.1 Key statistics: ECOWAS

\begin{tabular}{l|l|l|l|l|l}
\hline & $\begin{array}{l}\text { Population (in } \\
100,000)\end{array}$ & $\begin{array}{l}\text { GDP per } \\
\text { capita PPP }\end{array}$ & $\begin{array}{l}\text { \% of under- } \\
\text { nourished }\end{array}$ & $\begin{array}{l}\text { Total } \\
\text { production (in } \\
1000 \mathrm{mt})\end{array}$ & $\begin{array}{l}\text { Import/ } \\
\text { production } \\
\text { (in } \%)\end{array}$ \\
\hline Benin & 10,323 & 1791 & 8.1 & 1667 & 21 \\
\hline Burkina Faso & 16,934 & 1634 & 25.9 & 4949 & 9 \\
\hline Cape Verde & 498 & 6412 & - & 7 & 2.86 \\
\hline Cote d'Ivoire & 20,316 & 3012 & 21.4 & 1276 & 116 \\
\hline Gambia, The & 1849 & 1666 & 14.4 & 214 & 58 \\
\hline Ghana & 25,904 & 3974 & 3.4 & 2645 & 44 \\
\hline Guinea & 11,745 & 1255 & 17.3 & 2292 & 21 \\
\hline Guinea-Bissau & 1704 & 1242 & 8.7 & 175 & 74 \\
\hline Liberia & 4294 & 878 & 31.4 & 150 & 227 \\
\hline Mali & 15,301 & 1641 & 7.9 & 5032 & 3 \\
\hline Niger & 17,831 & 913 & 12.6 & 4308 & 13 \\
\hline Nigeria & 173,615 & 5863 & 8.5 & 22,042 & 32 \\
\hline Senegal & 14,133 & 2269 & 20.5 & 1182 & 150 \\
\hline Sierra Leone & 6092 & 1927 & 28.8 & 897 & 28 \\
\hline Togo & 6816 & 1390 & 16.5 & 1142 & 23 \\
\hline Total ECOWAS & 327,355 & 4123 & 12 & 47,978 & 30 \\
\hline Cameroon & 22,253 & 2711 & 15.7 & 3047 & 37 \\
\hline Chad & 12,825 & 2081 & 33.4 & 1647 & 18 \\
\hline Mauritania & 3889 & 3042 & 9.3 & 222 & 207 \\
\hline Soure: AFD & $2014), v 07$ & & & & \\
\hline
\end{tabular}

Source: AFDB (2014), von Grebmer et al. (2013), USDA (2014). Note: Mauritania withdrew from ECOWAS in 2000; CFA countries are Benin, Burkina Faso, Cameroon, Chad, Cote d'Ivoire, Guinea-Bissau, Mali, Mauritania, Niger, and Senegal; all other countries use their own free floating currency

trend clearly does not fit the supply data of several countries in the region. Therefore, the data is detrended by using the Hodrick-Prescott filter (HP-filter). ${ }^{5}$

An example is given in Fig. 15.1, which shows the national supply in Ghana. Actual supply quantities are depicted by the black line, and the dashed gray line indicates the HP-filter trend values for a smoothing parameter of 6.25. The deviation of actual supply from trend supply becomes stationary, and variability can be computed by:

$$
\mathrm{CV}=\sqrt{1 / n \sum\left(\mu-X_{t} / \overline{S_{t}}\right)^{2}} / \mu
$$

\footnotetext{
${ }^{5}$ The HP-filter is widely used to detrend macroeconomic time series data that exhibits cyclical fluctuations. The estimated trend value is given by the minimization of quadratic deviations in due consideration of a smooth trend. As recommended for annual data, the smoothing parameter is chosen to be 6.25 (Gabler Wirtschatfslexikon 2014).
} 


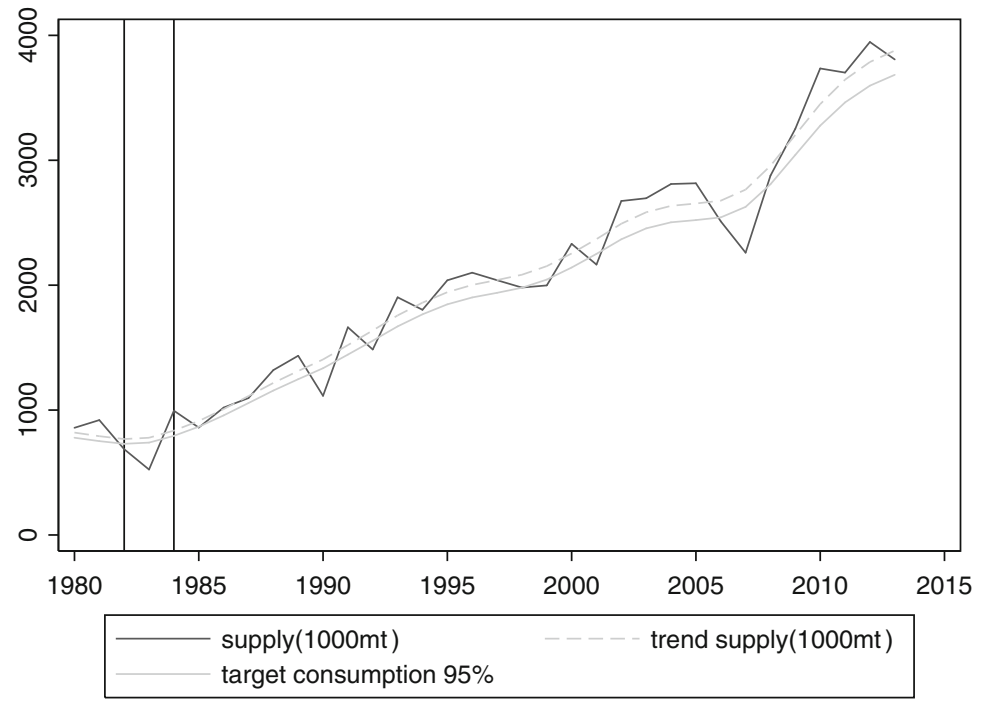

Fig. 15.1 Grain supply in Ghana 1980-2014. Source: Author's illustration based on USDA (2014)

where $X_{t}$ is the total supply in $t$ and $\overline{X_{\mathrm{t}}}$ the trend value of supply determined by the HP-filter. By definition, $\mu$ equals 1.

Table 15.2 shows each country's contribution to the total regional grain supply in 2014 as well as the coefficient of variation in production and supply over the period from 1980 to 2014. In brief, there are two general observations. First, supply variability is substantially lower than production variability, in particular for countries with high import-production ratio. Second, no country exhibits production and supply variability that is lower than the figure for the region as a whole. Therefore, the basic requirements for the West African region to benefit from cooperation are fulfilled.

In more detail, production variability is highest for Cape Verde, Mauritania, Senegal, the Gambia, and Chad. All these countries largely depend on import. However, for all of these countries, supply variability is significantly lower. This implies that imports were successfully utilized to stabilize domestic consumption, but the import levels are still higher than in countries with greater self-sufficiency. In general, coastal countries show higher production and supply stability; this can be explained by more favorable climatic conditions in the humid and semi-humid tropical zone compared to the Sahel zone (HarvestChoice 2014). Interestingly, these findings with regard to instability are quite similar to those of Koester (1984), who looks at the period from 1960 to 1980 . According to his analysis of the UEMOA countries, Burkina Faso, Cote d'Ivoire, and Mali had more stable production than Senegal, Mauritania, and Niger. The observed pattern seems to persist over time. 
Table 15.2 Production and supply instability in West Africa

\begin{tabular}{|c|c|c|c|c|}
\hline & $\begin{array}{l}\text { Share in regional } \\
\text { production }\end{array}$ & $\mathrm{CV}$ production & $\begin{array}{l}\text { Share in regional } \\
\text { supply }\end{array}$ & CV supply \\
\hline Benin & 2.9 & 7.6 & 2.7 & 7.6 \\
\hline Burkina Faso & 8.9 & 10.3 & 7.5 & 9.1 \\
\hline Cameroon & 5.7 & 7.2 & 6.0 & 6.0 \\
\hline Cape Verde & 0.0 & 43.8 & 0.0 & 30.3 \\
\hline Chad & 3.4 & 15.7 & 3.0 & 13.3 \\
\hline Cote d'Ivoire & 2.4 & 5.5 & 4.0 & 5.7 \\
\hline Gambia, The & 0.4 & 16.1 & 0.5 & 14.4 \\
\hline Ghana & 5.0 & 14.0 & 5.6 & 10.2 \\
\hline Guinea & 4.2 & 5.5 & 3.9 & 5.6 \\
\hline Guinea-Bissau & 0.4 & 9.8 & 0.4 & 10.3 \\
\hline Liberia & 5.0 & 16.1 & 0.7 & 14.8 \\
\hline Mali & 10.4 & 9.7 & 8.1 & 9.4 \\
\hline Mauritania & 0.4 & 27.6 & 1.0 & 9.6 \\
\hline Niger & 8.7 & 13.5 & 7.4 & 12.0 \\
\hline Nigeria & 40.6 & 5.8 & 41.2 & 5.4 \\
\hline Senegal & 2.4 & 18.0 & 4.3 & 8.3 \\
\hline Sierra Leone & 1.5 & 13.8 & 1.6 & 11.1 \\
\hline Togo & 2.1 & 10.2 & 2.0 & 8.1 \\
\hline Region & 100.0 & 4.5 & 100.0 & 3.4 \\
\hline
\end{tabular}

Source: Author's computation based on USDA (2014)

\subsubsection{Emergency Reserve}

This subsection discusses the optimal stocking norms for an emergency reserve as defined earlier. The target consumption level is the critical parameter to be chosen. A target consumption level of $j \%$ can be represented by $j \%$ of annual production (dashed line in Fig. 15.1). ${ }^{6}$ The lighter solid line in Fig. 15.1 illustrates this for a target consumption level of $95 \%$. Then, the deviation of actual supply from target consumption is computed, and the maximum historical shortfall is identified. In the instance of Ghana, the largest shortfall happened in 1983. The size of the shortfall depends on the target consumption chosen. Target consumption levels of individual countries are hypothetical and cannot be observed. A possible way to determine target consumption levels is to assume that each country uses the reserve to mitigate $x$ - $\%$ of the largest supply or production shock. From the standard deviation of these shocks of each country, the target consumption level with respect to any quantile can be computed. Normalized standard deviations are equal to the coefficient of variation shown in Table 15.2. Figure 15.2 shows the target consumption levels

\footnotetext{
$\overline{{ }^{6} \text { Recall that production/supply }}=$ consumption.
} 


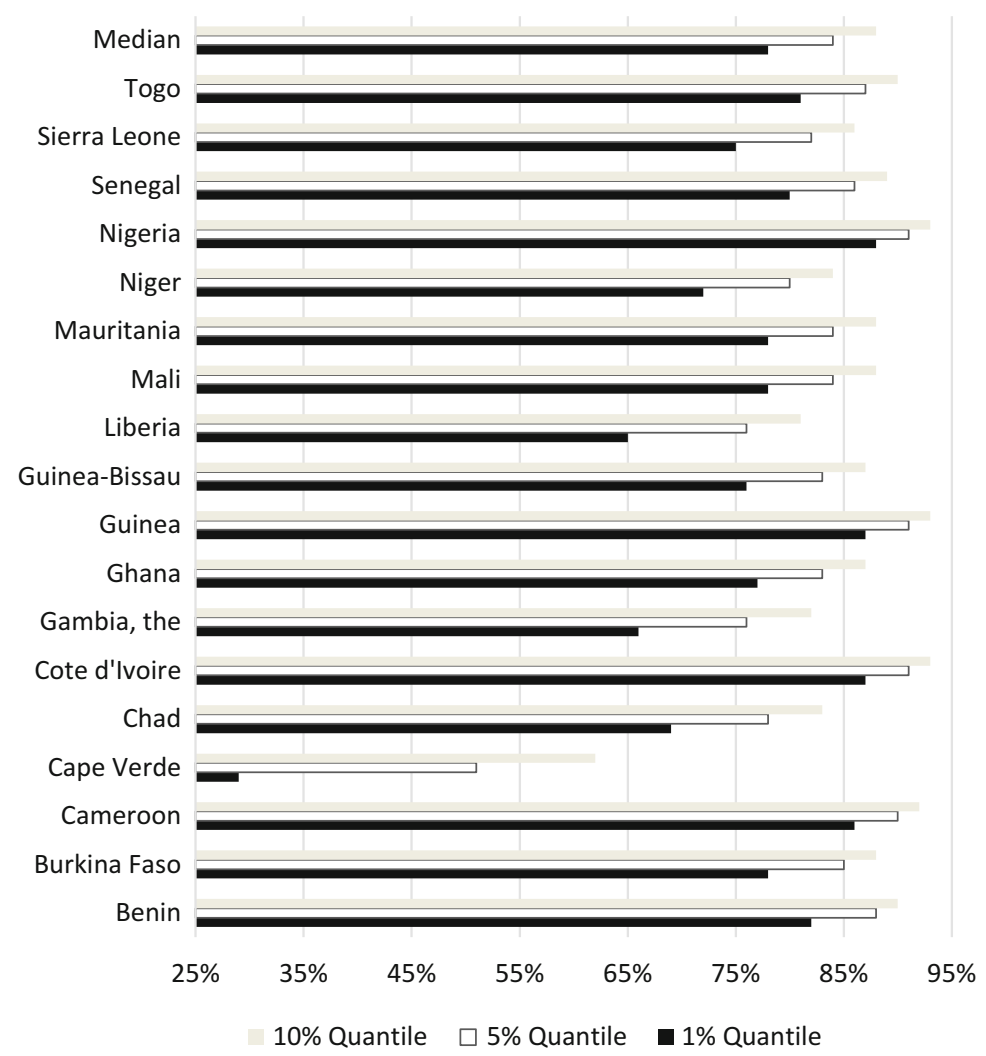

Fig. 15.2 Possible target consumption levels by country. Source: Author's illustration

across countries for the $1 \%, 5 \%$, and $10 \%$ quantiles when assuming a normal distribution of supply shocks. ${ }^{7}$

Figure 15.2 contains important information. Intuitively, the larger the tail of the distribution (the greater the quintile), the lower target consumption will be. First, as elaborated above, higher target consumption levels also require larger stocking norms. Second, target consumption levels would vary significantly among the countries: Nigeria, Cote d'Ivoire, and Guinea would have the highest target consumption levels, and Cape Verde would have the lowest. Third, the lower the national supply variability, the higher the target consumption levels in a particular quintile. This is also intuitive because when national supply is more stable, higher target consumption is required to alleviate a relatively moderate supply shock. In

\footnotetext{
${ }^{7} 1 \%, 5 \%$, and $10 \%$ quantiles reflect the frequency of interventions of the national reserve. Thus, absorbing the $10 \%$ largest supply shocks demands the highest frequency of supply shocks.
} 
the following, the median values will serve as possible target consumption levels for the region.

\subsubsection{Emergency Reserve Without Intra-regional Trade}

The stocking norm is defined as the largest historical shortfall between actual and target consumption over the past 35 years. Table 15.3 summarizes the respective stocking norms for all countries and various levels of target consumption. Apart from the median target consumption levels, the target consumption levels of $99 \%$, $97 \%, 95 \%$, and $90 \%$ are also considered.

Large countries have the highest optimal stocking norms. The corresponding stock-to-use ratios show the relative level of the stocking norms. All countries that are characterized by high supply variability also have the largest optimal stocking norms within an emergency reserve. The total regional stocks according to the maximum historical shortfall rule are between 231,137 tons and 6.2 million tons. The values for the target consumption levels of $95 \%$ and above are well in the range of the actual stock levels according to USDA and FAO CBS. However, one would choose optimal emergency reserve stocks that are smaller than actual stocks since total stocks also include speculative and working stocks of private market participants. In this respect, lower levels of target consumption seem to be more reasonable.

On the other hand, several countries with low supply variability hardly stock anything at target consumption levels below $95 \%$, as shown in Table 15.3. For instance, Nigeria and Guinea would not store anything at target consumption levels of $88 \%$ and below and thus would not benefit from regional storage with all stocking norms selected using the median values (shown in Fig. 15.2). At the target consumption level of $84 \%$, Cote d'Ivoire and Senegal would likely also cease to participate in a regional reserve, followed by Benin, Burkina Faso, Cameroon, Guinea-Bissau, Mali, and Togo for $78 \%$ target consumption. Hence, target consumption levels need to be sufficiently high in order that all West African countries benefit from cooperation. For this reason, only simulation results for target consumption levels of $90 \%$ and above are subsequently presented in the main text. The detailed simulation results for the target consumption level of $95 \%$ are tabulated in the main text in Table 15.4; the detailed results for $90 \%, 97 \%$, and $99 \%$ are presented in the Appendix (Tables 15.6, 15.7, and 15.8).

Under storage cooperation, optimal stocking norms can be significantly lower if shortfalls between actual and target consumption levels are independent or not perfectly positively correlated. The potential for the ECOWAS region to benefit from these independencies of production and supply shocks is underlined by the analysis conducted by Badiane et al. (2014).

Table 15.4 shows the results of having a regional reserve. For both production and supply, the remaining columns contain the optimal stocking norm under the following three scenarios: (1) no storage cooperation under autarky, (2) equal contributions from the countries to the regional reserve, and (3) relative contributions to the regional reserve required under autarky. The first column reveals the probability 


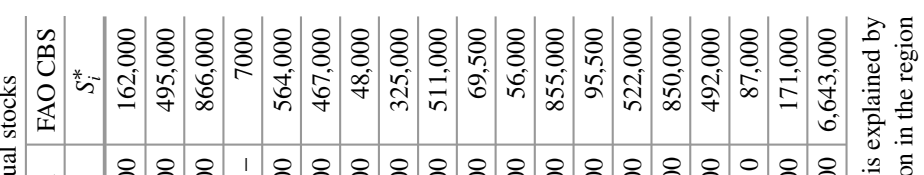

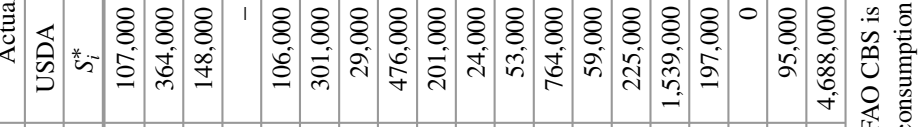

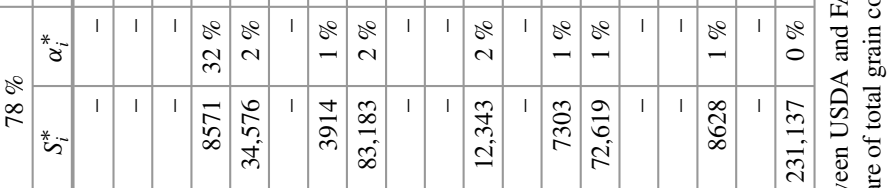
*

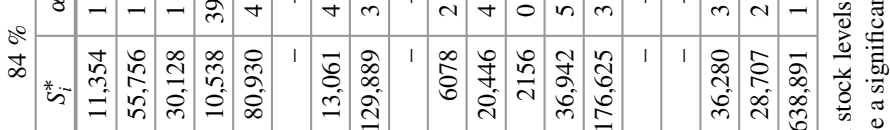

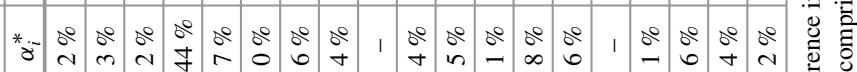

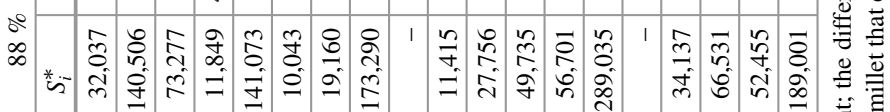
\& กิ 可

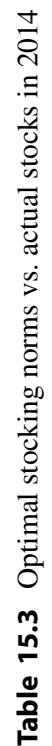

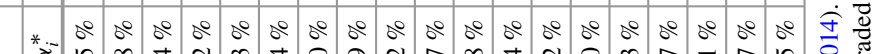

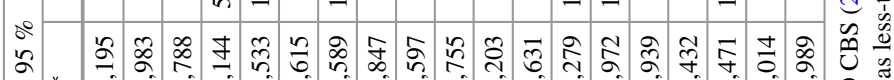
*

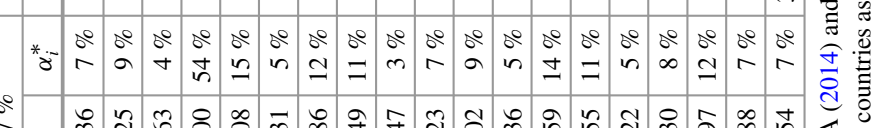

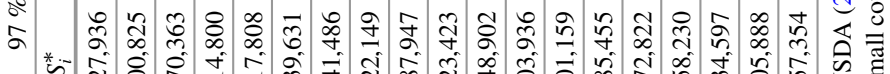

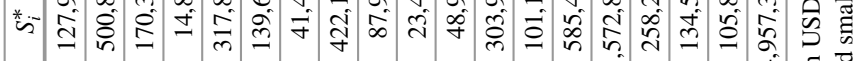

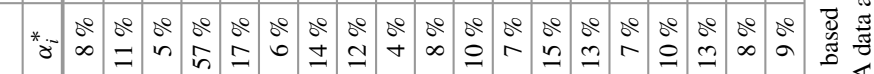

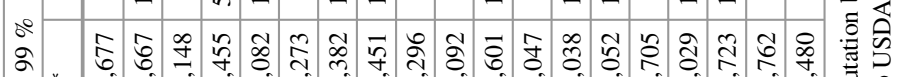

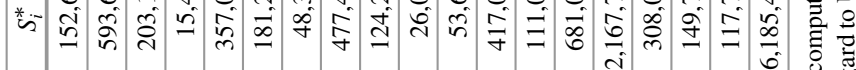


Table 15.4 Optimal stock levels in 2014 for target consumption of $95 \%$

\begin{tabular}{|c|c|c|c|c|c|c|c|c|}
\hline & \multicolumn{4}{|c|}{ Production } & \multicolumn{4}{|c|}{ Supply } \\
\hline & $P_{i}$ & $S_{i}^{*}$ & $\widehat{S}_{i}$ & $\widetilde{S}_{i}$ & $P_{i}$ & $S_{i}{ }^{*}$ & $\widehat{S}_{i}$ & $\widetilde{S}_{i}$ \\
\hline Benin & $26 \%$ & 98,832 & 68,249 & 58,004 & $29 \%$ & 103,195 & 66,181 & 66,804 \\
\hline Burkina Faso & $26 \%$ & 461,771 & 209,158 & 271,009 & $29 \%$ & 407,983 & 182,765 & 264,111 \\
\hline Cameroon & $11 \%$ & 163,986 & 134,570 & 96,242 & $14 \%$ & 148,788 & 146,499 & 96,319 \\
\hline Cape Verde & $43 \%$ & 7572 & 298 & 4444 & $40 \%$ & 14,144 & 885 & 9156 \\
\hline Chad & $37 \%$ & 301,534 & 79,510 & 176,968 & $31 \%$ & 278,533 & 73,389 & 180,311 \\
\hline Cote d'Ivoire & $14 \%$ & 84,520 & 55,554 & 49,604 & $20 \%$ & 99,615 & 97,416 & 64,487 \\
\hline Gambia, The & $34 \%$ & 70,230 & 9566 & 41,217 & $43 \%$ & 34,589 & 12,069 & 22,391 \\
\hline Ghana & $17 \%$ & 287,853 & 118,080 & 168,939 & $26 \%$ & 366,847 & 136,789 & 237,481 \\
\hline Guinea & $17 \%$ & 57,988 & 99,377 & 34,033 & $14 \%$ & 51,597 & 96,782 & 33,402 \\
\hline Guinea-Bissau & $29 \%$ & 21,528 & 7566 & 12,635 & $31 \%$ & 20,755 & 10,768 & 13,436 \\
\hline Liberia & $31 \%$ & 20,306 & 7941 & 11,918 & $31 \%$ & 44,203 & 18,083 & 28,615 \\
\hline Mali & $37 \%$ & 216,774 & 243,921 & 127,223 & $31 \%$ & 223,631 & 199,491 & 144,770 \\
\hline Mauritania & $46 \%$ & 49,666 & 9552 & 29,149 & $29 \%$ & 91,279 & 25,604 & 59,090 \\
\hline Niger & $29 \%$ & 607,626 & 204,524 & 356,610 & $31 \%$ & 503,972 & 182,173 & 326,251 \\
\hline Nigeria & $17 \%$ & 928,445 & 951,527 & 544,897 & $14 \%$ & 977,939 & $1,010,583$ & 633,077 \\
\hline Senegal & $40 \%$ & 429,613 & 56,908 & 252,136 & $26 \%$ & 208,432 & 106,131 & 134,930 \\
\hline Sierra Le & $31 \%$ & 105,992 & 35,788 & 62,206 & $31 \%$ & 119,471 & 38,301 & 77,341 \\
\hline Togo & $23 \%$ & 75,671 & 49,553 & 44,411 & $20 \%$ & 94,014 & 48,925 & 60,861 \\
\hline Total & $97 \%$ & $3,989,905$ & $2,342,642$ & $2,342,642$ & $97 \%$ & $3,788,989$ & $2,452,834$ & $2,452,834$ \\
\hline
\end{tabular}

Source: Author's computation based on USDA (2014). Note: Stock levels in mt; $P_{i}$ is the probability of intervention when production and supply are below the target consumption (99\%). $S_{i}{ }^{*}, \widehat{S}_{i}, \widetilde{S}_{i}$ are stocks without cooperation and with equal and relative contributions

of a shortfall in production and supply. ${ }^{8,9}$ The last row contains the total stock level of the whole region if the countries operate individual reserves and if they cooperate. Without regional storage cooperation, the total regional stocks amount to 3,989,905 metric tons for production only and 3,788,989 metric tons for supply. In contrast, with cooperation, regional stocks only need to be 2,342,642 and 2,452,834 metric tons. Comparing the two scenarios reveals a $41 \%$ and $35 \%$ reduction in the total storage level for production and supply, respectively. Since relative contributions among the countries imply that all countries benefit equally from the cooperation, the percentage reduction in storage levels applies to all countries alike. The positive effect of a regional storage cooperation holds regardless of the rule of contributions (equal or relative), but two countries, namely, Guinea and Nigeria, are disadvantaged in the case of proportionally equal contributions. Figure 15.3 shows the difference between the effects of both types of contributions on each country. It becomes evident that countries with relatively low levels of supply variability would prefer

\footnotetext{
${ }^{8}$ Equal contributions imply, proportionally equal to a country's share in regional consumption.

${ }^{9}$ The probability of shortfall is computed from historical shortfalls.
} 


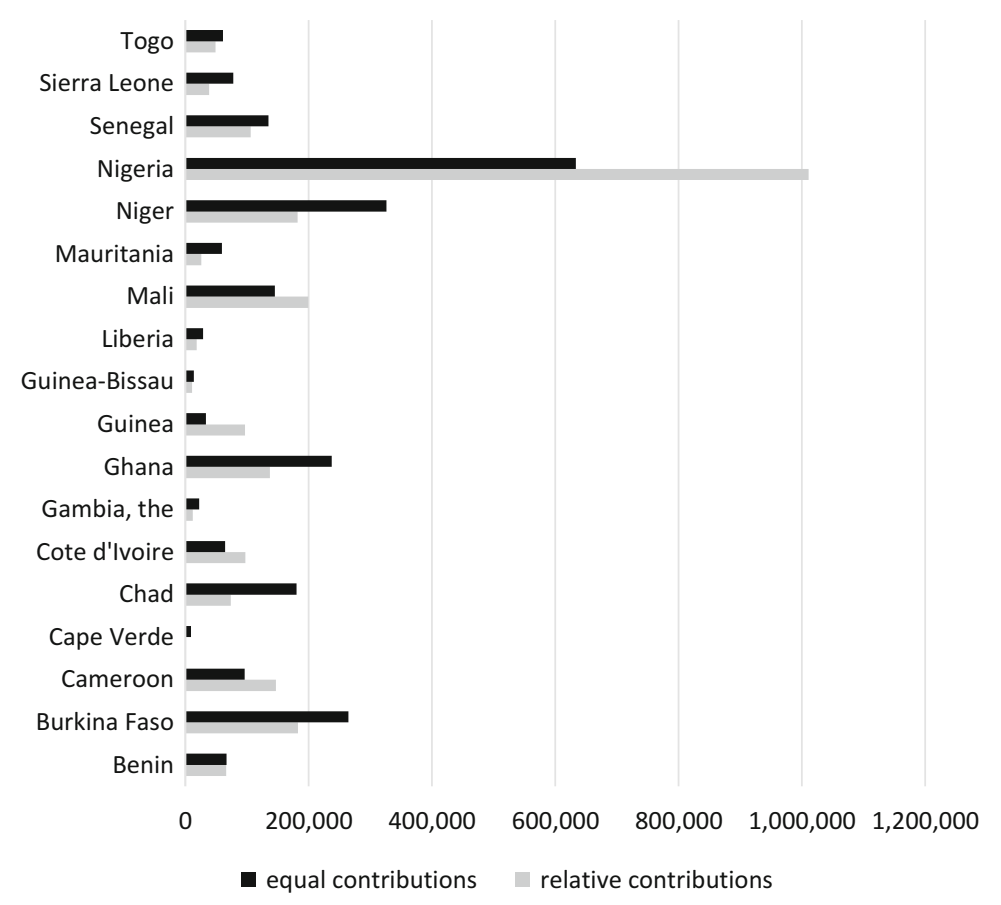

Fig. 15.3 Contributions to a regional reserve with $95 \%$ target consumption by country (based on supply). Source: Author's illustration based on USDA (2014). Note: Equal contributions to the reserve imply an identical stock-to-use ratio across countries, while relative contributions demand higher stock-to-use ratios in countries with higher variability in supply

relative contributions to the regional reserve. Nigeria, the single largest contributor, could save more than 300,000 metric tons of food when making relative as opposed to equal contribution. Similarly, Guinea, Cote d'Ivoire, Mali, and Cameroon would be able to reduce their contributions under the relative contribution scheme. In fact, the average stock-to-use ratio in the region ( $5 \%$ for $95 \%$ target consumption) represents a threshold. Without regional cooperation, all countries that have a stockto-use ratio above the regional average are better off by adopting equal instead of relative contributions, while all countries with a stock-to-use ratio below regional average would prefer relative contributions.

For clarity, the tabulated results for the other target consumption levels are only presented in the appendix. However, their effect on total regional stocks is illustrated in Fig. 15.4. The benefits of cooperation are lower at higher levels of target consumption. At $99 \%$ and $97 \%$ target consumption, regional stocks were, respectively, around $25 \%$ and $30 \%$ lower with cooperation than without cooperation, whereas the benefits of cooperation are greater at the target consumption of $90 \%$. Accordingly, regional stocks could be $62 \%$ lower with regional cooperation in contrast with without cooperation. 


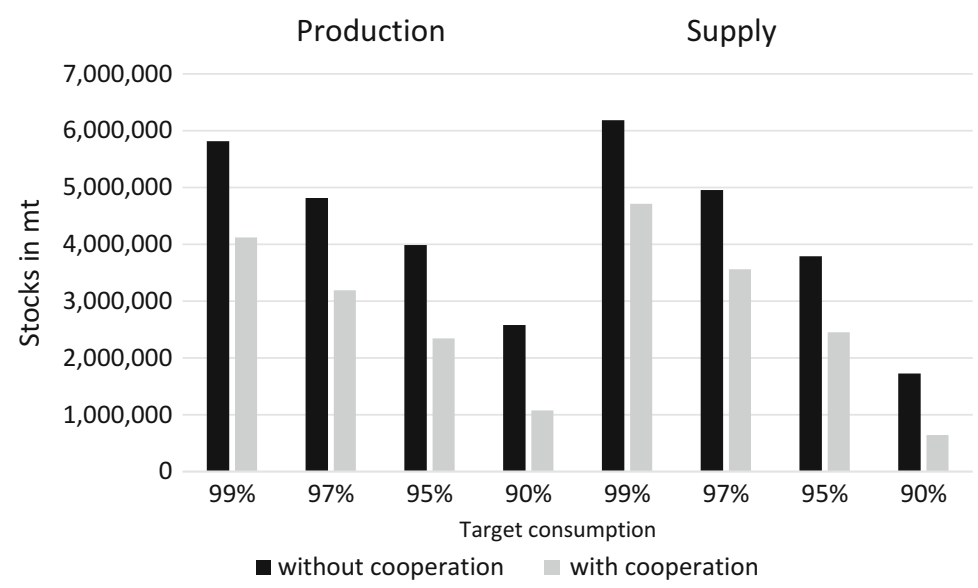

Fig. 15.4 Regional stocks with and without storage cooperation (without intra-regional trade). Source: Author's illustration based on USDA (2014)

It is noteworthy that a regional reserve without integration of markets or transfers between countries is required to act significantly more often than a national reserve as the probability of shortfalls increases. Hence, the total quantity needed to compensate for production and supply shortfalls is equal with or without storage cooperation. The benefits of cooperation are apparent only when lower stock levels are kept at any one time. However, these benefits are substantial as countries are also required to renew their reserve stocks on a regular basis, even if the reserve stocks are not used to offset supply shocks.

Lastly, what are the welfare implications that can be derived from the simulation results above? First and foremost, with reasonably high levels of target consumption, optimal stocking norms can be defined so that all countries would benefit from the decision. However, preferences are not homogeneous, and low levels of target consumption put countries with low supply variability at a disadvantage. Since the preferences of countries cannot be observed, only under two circumstances can net benefits be identified when preferences are heterogeneous. First, target consumption chosen by the region is lower than that of a country without cooperation, while stocking norms are lower with cooperation; in this case, a country benefits from cooperation. Second, the net benefits of cooperation are unambiguously negative if target consumption with cooperation is higher than with regional cooperation and if stocking norms are higher than without cooperation. Indeed, the latter can be excluded by choosing target consumption levels above $90 \%$. Intuitively, countries with large supply variability would likely prefer equal contribution to the regional reserve. Therefore, it is important to offer incentives for all countries to participate in the reserve in order to realize the full benefits of cooperation. 


\subsubsection{Emergency Reserve with Intra-Regional Trade}

When intra-regional trade is allowed, the analysis is analogous to the scenario without trade. Therefore, the largest historical shortfalls and the associated stocking norms in autarky remain unchanged. The only difference is that supply shortfalls in neighboring countries are first alleviated through trade before releasing stocks from the reserve. Participating countries are committed to export only when actual supply exceeds estimated supply as computed by the HP-filter.

Figure 15.5 shows a comparison of the required stocks with and without intraregional trade. Trade appears to hardly reduce the level of required stocks. The most notable gains are seen when stocks are based on a consumption shortfall of $10 \%$.

The results of the simulation can be explained by the choice of the criterion used to determine reserve levels according to historical consumption shortfalls. The historically largest shortfall occurred in 2007, and only very few countries were able to export in that year. The exports from these very few countries are not high enough to offset the supply shortfalls of other countries. Small differences in the reserve level notwithstanding, regional trade would reduce the frequency of stock-outs significantly. The probability of a shortfall occurring is at most $43 \%$, compared to between $89 \%$ and $100 \%$ across all levels of target consumption for the emergency reserve without intra-regional trade. When $5 \%$ shortfall in consumption is allowed, with intra-regional trade, the probability of a shortfall is only between $20 \%$ and $26 \%$ for supply and production, respectively.

These benefits are founded on intra-regional exports. Figure 15.6 shows the average annual exports, based on production and supply figures, over the period

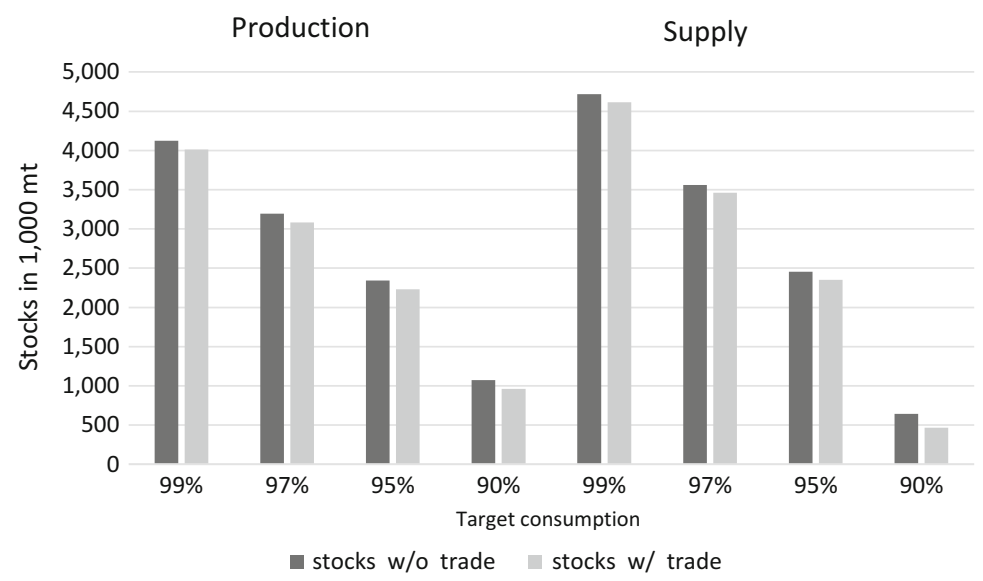

Fig. 15.5 Regional stocks for an emergency reserve with intra-regional trade. Source: Author's illustration based on USDA (2014) 


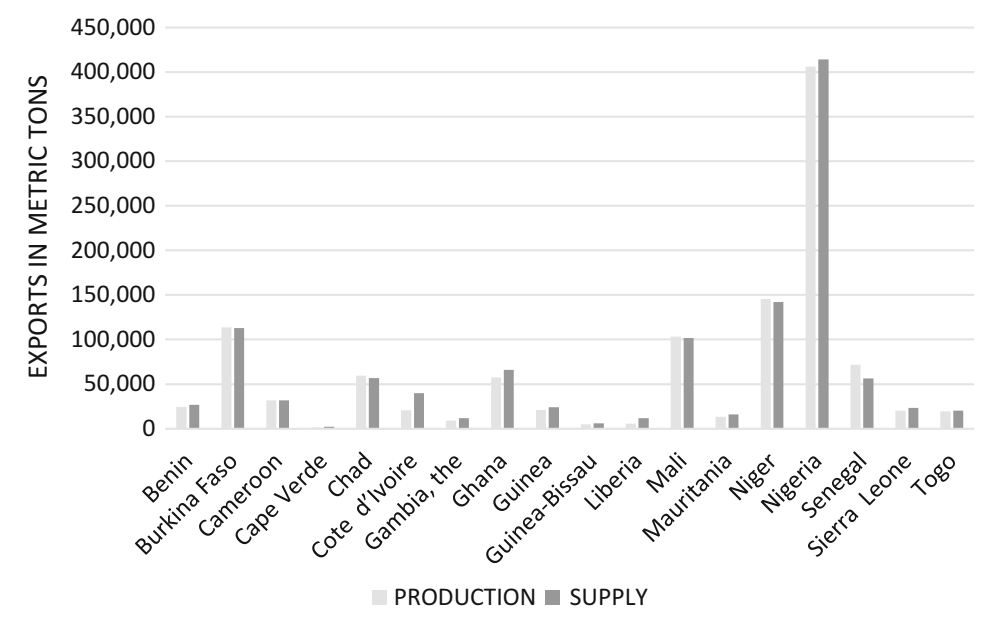

Fig. 15.6 Average annual exports by country 1980-2014. Source: Author's illustration based on USDA (2014)

from 1980 to 2014. The total annual exports amounted to 1.13 million tons based on production and 1.16 million tons based on supply data. As calculated using the expected supply for 2014 , the total annual exports range between $0.7 \%$ and $0.9 \%$ of total supply in 2014 for Guinea and Cameroon and between $4.59 \%$ and $7.9 \%$ for Cape Verde. By the definition used to determine exports, countries with higher production and supply fluctuations automatically export more than countries with lower fluctuations. This is because these countries exhibit greater positive and negative deviations from the trend. Generally, exports are at a realistic level. Net welfare benefits can be computed in a way similar to the case without intra-regional trade.

\subsubsection{Stabilization Reserve}

The optimal stocking rule under national stockholding can be estimated using actual stock data. Since the USDA only has poor quality of data on stocks for small countries, the FAO CBS stock data is preferred and utilized in this analysis. The stocking parameter is obtained by estimating the following equation with OLS:

$$
S_{t}=\gamma\left(S_{t-1}+Q_{t-1}+\mathrm{IM}_{t-1}-\mathrm{EX}_{t-1}\right)+\varepsilon_{t}
$$

where all variables are as described in the previous sections and $\varepsilon_{t}$ is the normally distributed error term.

It should be noted that the constant is omitted in this estimation. First, storage is a nonnegative value, and negative stocks values are also impossible. Second, stocks 


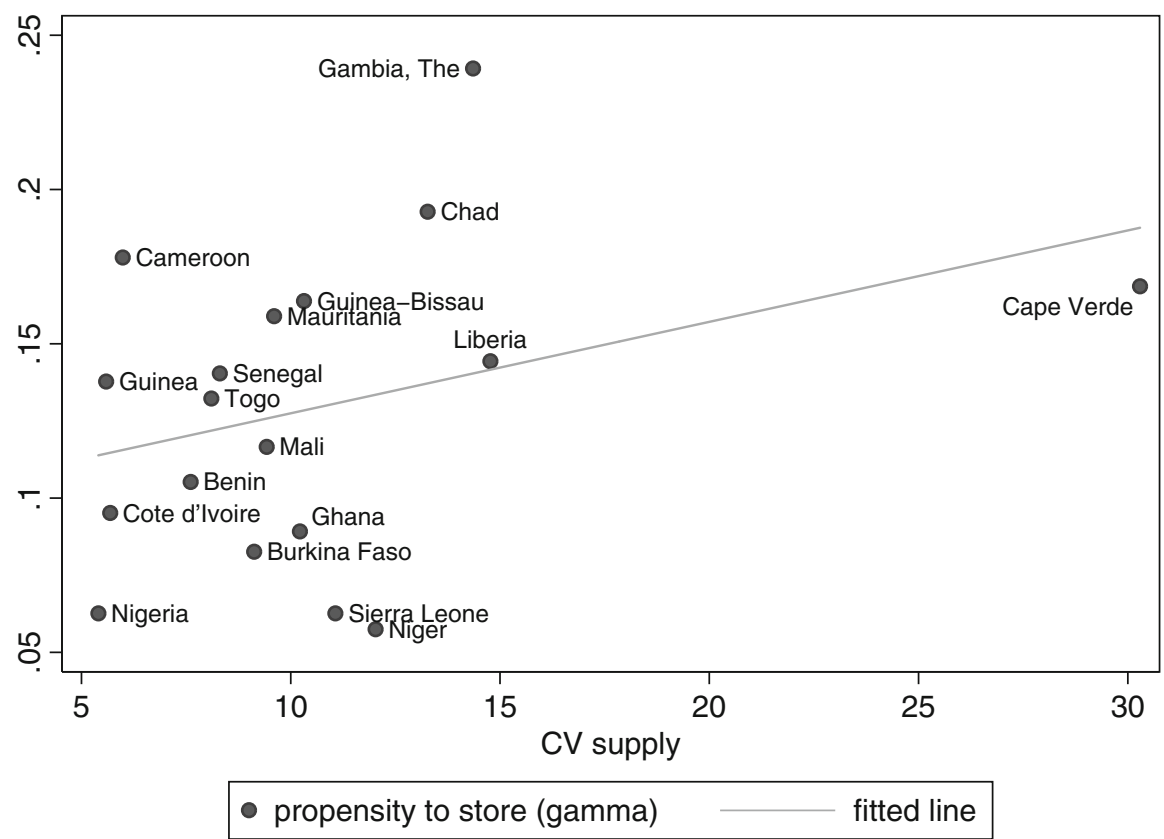

Fig. 15.7 Stocking parameter and supply variability across study countries. Source: Author's illustration based on USDA (2014) and FAO CBS (2014)

need to increase with supply starting from zero if supply is zero. ${ }^{10}$ The results are presented in Fig. 15.7, which depicts the stocking parameter $\gamma$ conditional on the level of supply variability estimated by the coefficient of variation around a trend as described in the previous sections.

The solid line represents the overall positive correlation between supply variability and the stocking rule. A slope parameter of 0.30 implies that the stocking parameter increases by 3 percentage points on average when supply variability is 10 percentage points higher. ${ }^{11}$ However, there are notable exceptions to this relationship. ${ }^{12}$ Niger, Sierra Leone, and Nigeria store only $6 \%$ of its total available supply, although their supply variability is relatively high. In contrast, the Gambia and Chad experience supply variability similar to Niger, but they store $24 \%$ and $19 \%$, respectively. All other countries in the region store roughly between 8 and

\footnotetext{
${ }^{10}$ The estimation is associated with several problems (non-stationarity, number of observations), and results have to be interpreted with caution. However, the objective is not to establish causality or to compute confidence intervals but rather to obtain a country's preferences without storage cooperation.

${ }^{11}$ When Cape Verde, an outlier, is excluded, the slope parameter only changes marginally.

${ }^{12}$ It should be noted that an increase of 0.1 is quite substantial because $\gamma$ ranges between 0 and 1 .
} 


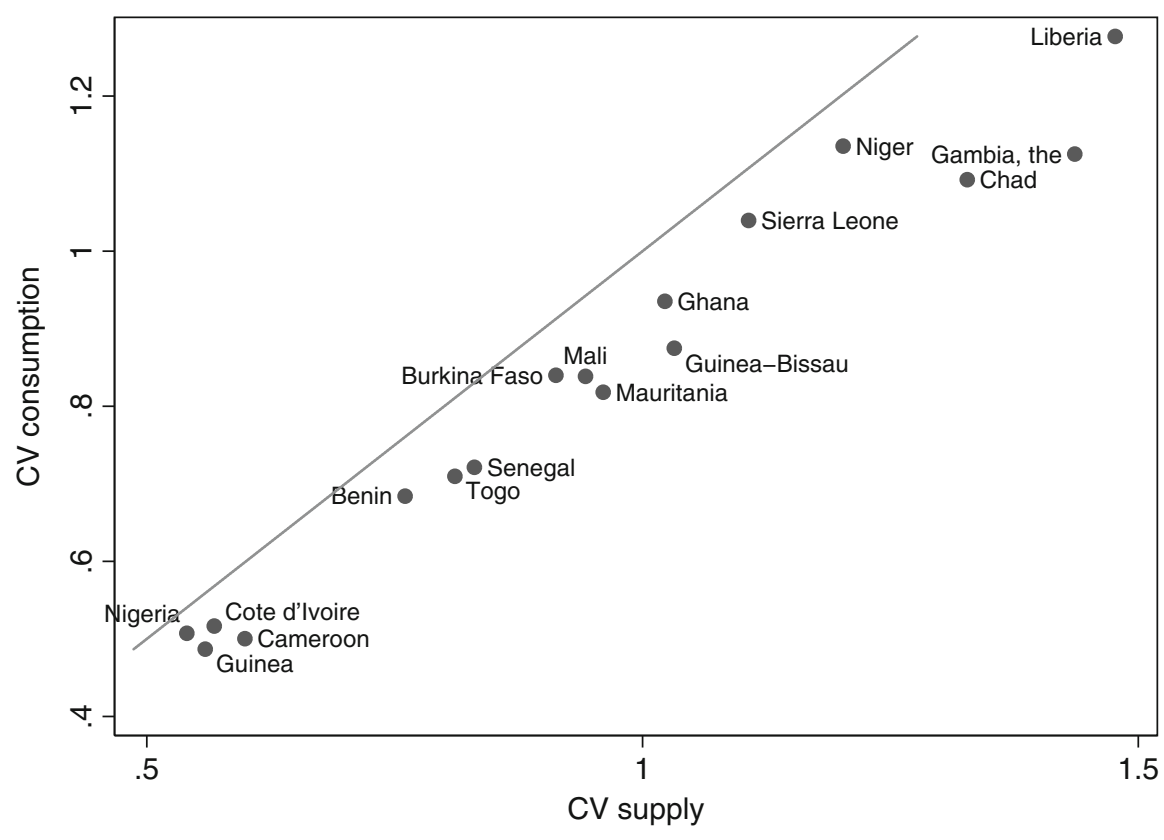

Fig. 15.8 Consumption and supply variability of study countries. Source: Author's illustration based on USDA (2014) and FAO CBS (2014)

$17 \%$. Taking the sum of individual stocks as the optimal choice for the region, $9 \%$ of the region's annual supply should be stored due to the low value of Nigeria.

Using the policy parameter and the information on each country's supply variability, it is possible to compute the consumption variability as chosen by each country (see Eq. 15.22). Figure 15.8 shows the relative position of each country with regard to their consumption and supply. The solid line represents the parity between consumption and supply variability; countries without storage would lie on this line. With additional storage, countries move further to the right, away from the solid line. Hence, the larger a country's stocking parameter $\gamma$ is, the farther away from the parity line countries are. Moreover, for countries with lower supply variability, it is less efficient to decrease consumption variability by one unit by increasing storage. For example, Cameroon needs to store $18 \%$ of its total available supply to reduce consumption variability by $1 \%$. In contrast, Ghana is able to reduce consumption instability by $0.8 \%$ by storing only $9 \%$ of its available supply.

The costs of stabilization are already described by the stocking parameter $\gamma$. The full dimension of the costs become more visible when looking at the amount of stocks required to reach a desired level of consumption stability. Table 15.5 presents the optimal stock levels and stock-to-use ratio for $\gamma$ calculated using country-level stock data and compares them to actual levels. The resulting stock-to-use ratio is $\alpha=\frac{\gamma}{1-\gamma}$, which has a positive exponential relationship with $\gamma$. When $\gamma>0.5$, stocks already amount to expected consumption levels with a stock-to-use ratio 
Table 15.5 Actual and optimal stock levels under a linear stocking rule

\begin{tabular}{l|r|r|r|r|r|r}
\hline & \multicolumn{1}{|c|}{$\gamma^{*}$} & \multicolumn{1}{c|}{$\mathrm{CV}_{\mathrm{c}}$} & \multicolumn{1}{c|}{$S^{*}$} & \multicolumn{1}{c|}{$S_{2013}$} & \multicolumn{1}{c}{$\alpha^{*}$} & $\frac{S_{2013}}{C}$ \\
\hline Benin & 0.105 & 6.8 & 220,802 & 162,000 & 11.8 & 12.8 \\
\hline Burkina Faso & 0.083 & 8.4 & 466,615 & 495,000 & 9.0 & 8.5 \\
\hline Cameroon & 0.178 & 5.0 & 899,228 & 866,000 & 21.7 & 16.0 \\
\hline Cape Verde & 0.169 & 25.5 & 5089 & 7000 & 20.3 & 20.3 \\
\hline Chad & 0.193 & 10.9 & 496,928 & 564,000 & 23.9 & 22.3 \\
\hline Cote d'Ivoire & 0.095 & 5.2 & 290,463 & 467,000 & 10.5 & 9.3 \\
\hline Gambia, The & 0.239 & 11.2 & 107,609 & 48,000 & 31.5 & 30.4 \\
\hline Ghana & 0.089 & 9.4 & 379,520 & 325,000 & 9.8 & 9.2 \\
\hline Guinea & 0.138 & 4.9 & 438,248 & 511,000 & 16.0 & 14.3 \\
\hline Guinea-Bissau & 0.164 & 8.7 & 59,828 & 69,500 & 19.6 & 17.3 \\
\hline Liberia & 0.144 & 12.8 & 86,482 & 56,000 & 16.9 & 14.7 \\
\hline Mali & 0.117 & 8.4 & 746,375 & 855,000 & 13.2 & 10.1 \\
\hline Mauritania & 0.159 & 8.2 & 137,177 & 95,500 & 18.9 & 20.7 \\
\hline Niger & 0.057 & 11.4 & 314,910 & 522,000 & 6.1 & 5.4 \\
\hline Nigeria & 0.063 & 5.1 & $1,915,352$ & 850,000 & 6.7 & 7.0 \\
\hline Senegal & 0.140 & 7.2 & 491,235 & 492,000 & 16.3 & 16.2 \\
\hline Sierra Leone & 0.063 & 10.4 & 72,532 & 87,000 & 6.7 & 5.3 \\
\hline Togo & 0.132 & 7.1 & 211,342 & 171,000 & 15.2 & 14.9 \\
\hline Region & - & 3.1 & $7,063,305$ & $6,643,000$ & - & 10.3 \\
\hline Source: Aut & & & & & & \\
\hline
\end{tabular}

Source: Author's computation based on USDA (2014) and FAO CBS (2014). Note: Country level $\gamma$ is obtained by the regression (15.24); $\mathrm{CV}$ consumption is computed as $\mathrm{CV}_{\mathrm{c}}=\sqrt{\frac{1-\gamma}{1+\gamma}} \mathrm{CV}(X)$ (see Eq. 15.22); the optimal regional $\gamma$ is unknown

greater than one. Notably, the linear stocking rule predicts actual stocks and stockto-use ratios quite precisely.

The last row in Table 15.5 provides stock figures for the region as a whole. Given the current stock level of around 7 million tons, the regional stocking rule would imply that $9 \%$ of the total supply needs to be stocked up. This is associated with a consumption variability of $3.4 \%$, as compared to $3.1 \%$ without storage. It is also possible to describe the initial optimization problem of governments directly as a trade-off between costs and benefits, more specifically, the trade-off between consumption stability and operational costs. Figure 15.9 shows the trade-off for the region as a whole. The dotted black line indicates the status quo - roughly 7 million tons of stocks associated with a coefficient of variation of consumption of $3.1 \%$. The dashed black line represents a stock level of 11.1 million tons resulting from a stocking parameter of 0.135 , which is the median parameter across all member countries.

The required amount of stocks increases overproportionally with a reduction in consumption instability. In order to reach consumption stability of up to only $2.7 \%$, the region would require roughly 20 million tons of stocks. When no stocks are required however, consumption variability through market integration or transfers between countries is only $3.4 \%$; this figure is $2 \%$ less for Nigeria, which has 


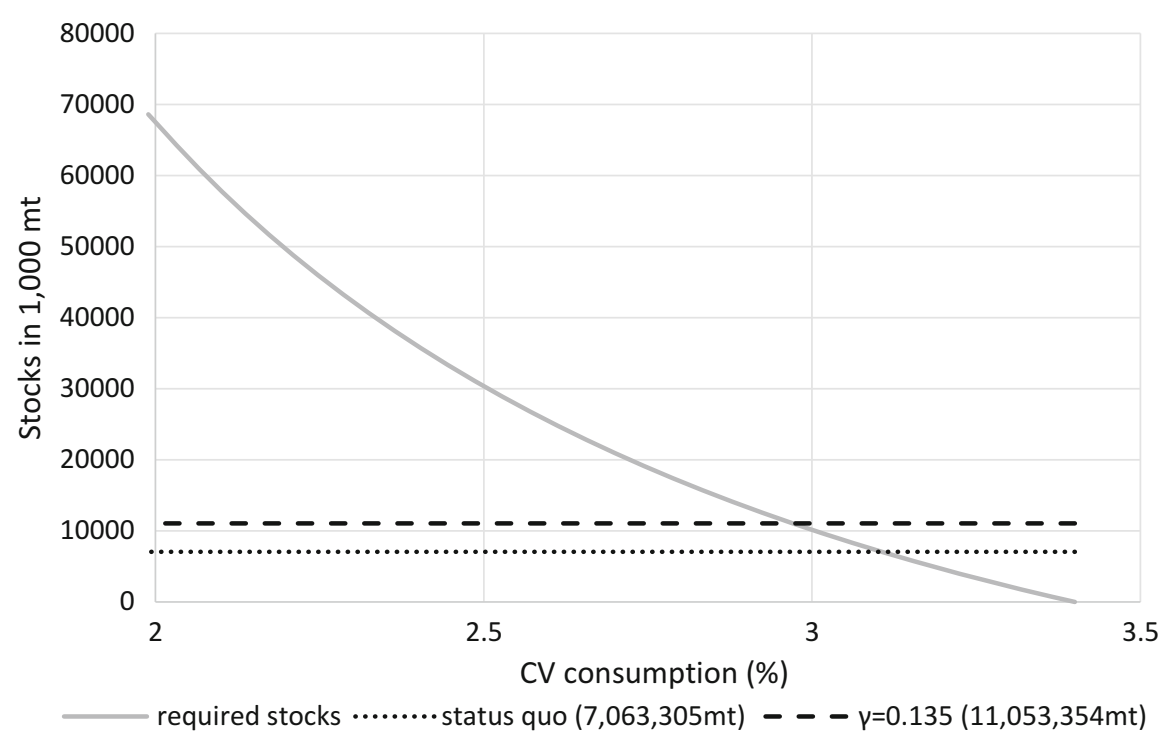

Fig. 15.9 Regional consumption variability at different stock levels. Source: Author's illustration based on USDA (2014) and FAO CBS (2014)

the lowest supply variability. This implies that most of the gains originate from trade integration and not from storage cooperation. In other words, consumption stability is largely enhanced by regional trade integration, but increasing stocks have only very little impact on the level of consumption variability. The benefits of regional trade cooperation are significant. Individual countries would need an unrealistically large amount of stocks in their stabilization reserve to achieve a consumption variability of $3.4 \%$. The costs and benefits of cooperation can be evaluated for a particular level of consumption variability which the region desires. We assume the observed stocking parameter is chosen as the optimal stocking rule by each country. Since trade integration is associated with huge benefits in the form of a reduction of consumption instability, a country in autarky may be worse off only if the regional stocking parameter exceeds the one chosen by the country. Hence, net benefits are strictly positive for all countries up to a stock-to-use ratio of $6.1 \%$ for Niger, $6.7 \%$ for Nigeria and Sierra Leone, $9.0 \%$ for Burkina Faso, and $9.8 \%$ for Ghana; in the same manner, the values for other countries are determined according to $\alpha_{i}^{*}$, as shown in Table 15.5.

Lastly, it is possible to test how a linear stocking rule would have performed over the course of the last 35 years. Figure 15.10 illustrates the performance in relation to the associated target consumption levels. Despite regional trade integration, the simulated regional consumption undershot target consumption levels of $99 \%, 97 \%$, 


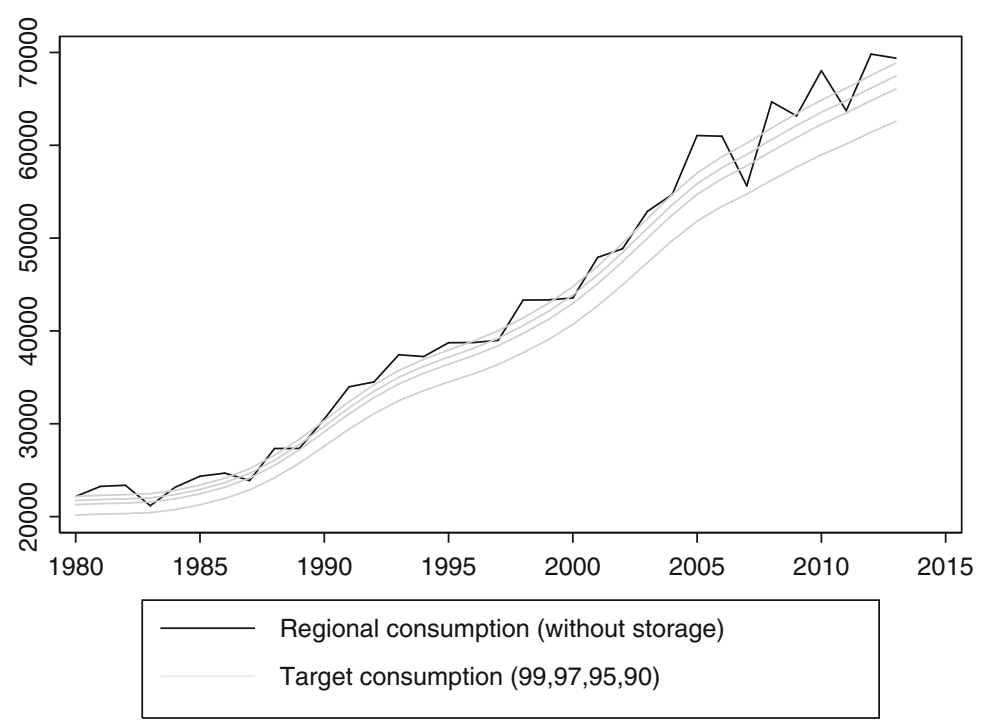

Fig. 15.10 Regional consumption under trade integration without storage. Source: Author's illustration based on USDA (2014) and FAO CBS (2014)

and $95 \%$ multiple times. ${ }^{13}$ Thus, regional trade integration reduces consumption variability significantly, but it is unable to combat severe supply shortfalls. Conversely, a linear stocking rule which guarantees that all countries achieve net benefits by cooperating ( $\alpha=6.1 \%$ ) would have a guaranteed target consumption of $97 \%$ over the whole period. Clearly, a linear stocking rule is effective in buffering positive and negative supply shock. However, the effects are rather small compared with the benefits of trade integration within the whole region. This may change if the number of participating countries reduces.

\subsection{Conclusion}

In this study, a methodology for assessing the costs and benefits of regional storage cooperation is outlined and applied to the West African region. Building on the influential works of Johnson (1976) and Koester (1986), the methodology establishes a link between supply and consumption variability, and it accounts for the potential benefits of cooperation through the imperfect correlation of production and supply shocks among neighboring countries. In doing so, the work complements previous studies by conceptualizing the link to storage.

\footnotetext{
${ }^{13}$ To be exact, the number of shortfalls are (accordingly to target consumption) $99 \%, 11$ times; $97 \%, 7$ times; $95 \%, 3$ times; and $90 \%$, never.
} 
The principles of risk pooling allow for reducing carry-over stocks by 35 $41 \%$ within West Africa without welfare transfers or trade between countries so as to guarantee at least $95 \%$ of the expected trend consumption. For other minimum consumption levels, the benefits are between $25 \%$ and $60 \%$. National contributions to the reserve can be organized in such a manner that all countries benefit significantly from the cooperation. However, in this way, releases from the reserve would occur frequently, and stocks would need to be refilled on a regular basis. If limited intra-regional trade takes place between areas with surplus and deficiency, the optimal regional stocks under cooperation hardly change. However, the need for stock release intervention reduces significantly. Therefore, trade is very effective in smoothing consumption when supply fluctuations are moderate. In contrast, reserves are required to dampen large supply shortfalls. These benefits are large enough to justify additional costs that may arise from storage cooperation. Lastly, complete market integration in West Africa would greatly benefit countries with high supply variability. Without undertaking any storage, regional supply variability is at $3.4 \%$, which is higher than that of each country included in the analysis. Storage cooperation beyond full market integration would reduce consumption variability only marginally. Furthermore, trade integration without storage, unlike an emergency reserve, is incapable of dampening severe supply shortfalls.

It is also important to consider offering incentives to countries to encourage them to participate in a regional reserve. When the level of target consumption is relatively low in an emergency reserve, countries with low supply variability do not benefit. Yet these countries are of particular importance to realize the full benefits of regional cooperation. The advantages of cooperation diminish rapidly when countries with limited supply variability or countercyclical shock patterns refuse to participate in the alliance. However, it should be noted that a regional emergency reserve guaranteeing relative high levels of target consumption needs to carry large amounts of stocks, which are associated with high operational costs.

These findings are of great relevance to the ongoing debate on public food storage, trade integration, and regional reserves. Trade liberalization is widely considered as an effective instrument to balance supply variability and production shortfalls. In contrast, public storage is associated with substantial market distortions and comes at high fiscal costs. Nevertheless, a number of developing countries responded to the global food crisis in 2007/2008 by implementing and enhancing public storage to increase food security. This is also driven by the unpredictability of food availability at international markets as exporters attempt to insulate domestic markets. Regional storage cooperation was brought up for discussion as viable and comparably cheap means of addressing a food crisis and as an alternative to national reserves. Moreover, storage cooperation could enhance commitment of exporters to regional trade agreements (Wright and Cafiero 2011). 
West Africa has taken a pioneering role by showing the intention to implement a region-wide emergency reserve. Political and economic integration in West Africa is among the most advanced in Africa. However, at present, intra-regional trade is limited partly because of bad infrastructure and bureaucratic hindrances at national boundaries. The results from this study should be understood as an encouragement to regional storage cooperation in the region. Three messages can be taken away from this study. First, production and supply patterns in the region are able to facilitate cooperation which may yield massive benefits. Second, trade integration is more effective than storage in smoothing supply, but storage is required to dampen extreme supply shortfalls. Last, there is great potential for storage cooperation with regard to an emergency reserve and less with regard to a stabilization reserve. Nevertheless, clear rules about individual country's contributions and releases, and, if needed, regional trade management, are essential to organize regional storage with mutual benefits. Administrative complexity is likely to be a smaller problem with a limited number of partner countries. Therefore, future research should attempt to evaluate the costs and benefits for subsets of countries in an attempt to identify the countries which could possibly form a coalition. Moreover, the potential benefit of intra-regional trade integration should be analyzed more rigorously.

Acknowledgment The author acknowledges financial support from the European Commission (FoodSecure Research Project) and the Federal Ministry for Economic Cooperation and Development of Germany (Research Project on Commodity Price Volatility, Trade Policy, and the Poor).

\section{Appendix}

Table 15.6 Optimal stock levels in 2014 for target consumption of $99 \%$

\begin{tabular}{l|c|r|r|r|c|r|r|r}
\hline & \multicolumn{4}{|c|}{ Production } & \multicolumn{4}{c}{ Supply } \\
\cline { 2 - 9 } & $P_{i}$ & \multicolumn{1}{|c}{$S_{i}{ }^{*}$} & \multicolumn{1}{c|}{$\widehat{S}_{i}$} & \multicolumn{1}{c}{$\widetilde{S}_{i}$} & $P_{i}$ & \multicolumn{1}{c}{$S_{i}{ }^{*}$} & \multicolumn{1}{c}{$\widehat{S}_{i}$} & \multicolumn{1}{c}{$\widetilde{S}_{i}$} \\
\hline Benin & $40 \%$ & 141,604 & 120,137 & 100,356 & $37 \%$ & 152,677 & 127,265 & 116,424 \\
\hline Burkina Faso & $40 \%$ & 631,234 & 368,174 & 447,361 & $40 \%$ & 593,667 & 351,453 & 452,700 \\
\hline Cameroon & $49 \%$ & 214,049 & 236,879 & 151,698 & $26 \%$ & 203,148 & 281,713 & 154,911 \\
\hline Cape Verde & $49 \%$ & 8101 & 524 & 5741 & $52 \%$ & 15,455 & 1701 & 11,785 \\
\hline Chad & $49 \%$ & 368,209 & 139,960 & 260,953 & $46 \%$ & 357,082 & 141,125 & 272,293 \\
\hline Cote d'Ivoire & $37 \%$ & 127,531 & 97,789 & 90,382 & $43 \%$ & 181,273 & 187,327 & 138,229 \\
\hline Gambia, The & $43 \%$ & 79,208 & 16,839 & 56,135 & $55 \%$ & 48,382 & 23,208 & 36,894 \\
\hline Ghana & $43 \%$ & 357,196 & 207,853 & 253,148 & $43 \%$ & 477,451 & 263,042 & 364,079 \\
\hline Guinea & $43 \%$ & 90,030 & 174,930 & 63,805 & $46 \%$ & 124,296 & 186,109 & 94,782 \\
\hline Liberia & $40 \%$ & 27,477 & 13,978 & 19,473 & $49 \%$ & 53,601 & 34,774 & 40,873 \\
\hline Mali & $58 \%$ & 419,760 & 429,367 & 297,487 & $55 \%$ & 417,047 & 383,615 & 318,019 \\
\hline
\end{tabular}


Table 15.6 (continued)

\begin{tabular}{l|c|r|r|r|r|r|r|r}
\hline & \multicolumn{4}{|c|}{ Production } & \multicolumn{4}{c}{ Supply } \\
\cline { 2 - 10 } & $P_{i}$ & \multicolumn{1}{c|}{$S_{i}{ }^{*}$} & \multicolumn{1}{c|}{$\widehat{S}_{i}$} & \multicolumn{1}{c}{$\widetilde{S}_{i}$} & \multicolumn{1}{c}{$P_{i}$} & \multicolumn{1}{c}{$S_{i}{ }^{*}$} & \multicolumn{1}{c}{$\widehat{S}_{i}$} & \multicolumn{1}{c}{$\widetilde{S}_{i}$} \\
\hline Mauritania & $49 \%$ & 56,683 & 16,814 & 40,172 & $46 \%$ & 111,038 & 49,237 & 84,672 \\
\hline Niger & $37 \%$ & 779,525 & 360,017 & 552,456 & $37 \%$ & 681,052 & 350,313 & 519,335 \\
\hline Nigeria & $43 \%$ & $1,786,527$ & $1,674,944$ & $1,266,127$ & $43 \%$ & $2,167,705$ & $1,943,323$ & $1,652,981$ \\
\hline Senegal & $49 \%$ & 477,554 & 100,173 & 338,447 & $52 \%$ & 308,029 & 204,087 & 234,887 \\
\hline Sierra Leone & $37 \%$ & 128,728 & 62,996 & 91,231 & $46 \%$ & 149,723 & 73,652 & 114,171 \\
\hline Togo & $43 \%$ & 95,910 & 87,226 & 67,972 & $40 \%$ & 117,762 & 94,081 & 89,800 \\
\hline Region & $100 \%$ & $5,816,099$ & $4,122,000$ & $4,122,000$ & $100 \%$ & $6,185,480$ & $4,716,730$ & $4,716,730$ \\
\hline
\end{tabular}

Source: Author's computation based on USDA (2014). Note: Stock levels in $\mathrm{mt} ; P_{i}$ is the probability of intervention when production and supply are below the target consumption (99\%). $S_{i}{ }^{*}, \widehat{S}_{i}, \widetilde{S}_{i}$ are stocks without cooperation and with equal and relative contributions

Table 15.7 Optimal stock levels in 2014 for target consumption of $97 \%$

\begin{tabular}{|c|c|c|c|c|c|c|c|c|}
\hline & \multicolumn{4}{|c|}{ Production } & \multicolumn{4}{|c|}{ Supply } \\
\hline & $P_{i}$ & $S_{i}{ }^{*}$ & $\widehat{S}_{i}$ & $\widetilde{S}_{i}$ & $P_{i}$ & $S_{i}{ }^{*}$ & $\widehat{S}_{i}$ & $\widetilde{S}_{i}$ \\
\hline Benin & $34 \%$ & 120,218 & 93,057 & 79,668 & $37 \%$ & 127,936 & 96,089 & 91,907 \\
\hline Burkina Faso & $34 \%$ & 546,502 & 285,182 & 362,163 & $37 \%$ & 500,825 & 265,358 & 359,785 \\
\hline Cameroon & $29 \%$ & 189,018 & 183,483 & 125,260 & $17 \%$ & 170,363 & 212,702 & 122,386 \\
\hline Cape Verde & $49 \%$ & 7836 & 406 & 5193 & $40 \%$ & 14,800 & 1285 & 10,632 \\
\hline Chad & $43 \%$ & 334,871 & 108,411 & 221,916 & $40 \%$ & 317,808 & 106,554 & 228,308 \\
\hline Cote d'Ivoire & $23 \%$ & 106,025 & 75,746 & 70,262 & $31 \%$ & 139,631 & 141,438 & 100,309 \\
\hline Gambia, The & $37 \%$ & 74,719 & 13,043 & 49,515 & $54 \%$ & 41,486 & 17,523 & 29,803 \\
\hline Ghana & $37 \%$ & 317,677 & 161,000 & 210,522 & $34 \%$ & 422,149 & 198,605 & 303,265 \\
\hline Guinea & $34 \%$ & 74,009 & 135,498 & 49,045 & $31 \%$ & 87,947 & 140,519 & 63,179 \\
\hline Guinea-Bissau & $34 \%$ & 24,150 & 10,316 & 16,004 & $40 \%$ & 23,423 & 15,634 & 16,827 \\
\hline Liberia & $40 \%$ & 23,892 & 10,827 & 15,833 & $37 \%$ & 48,902 & 26,255 & 35,130 \\
\hline Mali & $46 \%$ & 309,623 & 332,581 & 205,185 & $49 \%$ & 303,936 & 289,642 & 218,342 \\
\hline Mauritania & $49 \%$ & 53,175 & 13,024 & 35,238 & $37 \%$ & 101,159 & 37,175 & 72,671 \\
\hline Niger & $34 \%$ & 693,576 & 278,864 & 459,627 & $34 \%$ & 585,455 & 264,498 & 420,581 \\
\hline Nigeria & $34 \%$ & $1,285,869$ & $1,297,387$ & 852,134 & $34 \%$ & $1,572,822$ & $1,467,271$ & $1,129,890$ \\
\hline Senegal & $43 \%$ & 453,584 & 77,593 & 300,586 & $43 \%$ & 258,230 & 154,092 & 185,508 \\
\hline Sierra Leone & $34 \%$ & 117,360 & 48,796 & 77,773 & $40 \%$ & 134,597 & 55,609 & 96,692 \\
\hline Togo & $31 \%$ & 85,791 & 67,564 & 56,853 & $29 \%$ & 105,888 & 71,035 & 76,069 \\
\hline Region & $100 \%$ & $4,817,894$ & $3,193,000$ & $3,193,000$ & $97 \%$ & $4,957,355$ & $3,561,283$ & $3,561,283$ \\
\hline
\end{tabular}

Source: Author's computation based on USDA (2014). Note: Stock levels in $\mathrm{mt} ; P_{i}$ is the probability of intervention when production and supply are below the target consumption $(99 \%) . S_{i}{ }^{*}, \widehat{S}_{i}, \widetilde{S}_{i}$ are stocks without cooperation and with equal and relative contributions 
Table 15.8 Optimal stock levels in 2014 for target consumption of $90 \%$

\begin{tabular}{|c|c|c|c|c|c|c|c|c|}
\hline & \multicolumn{4}{|c|}{ Production } & \multicolumn{4}{|c|}{ Supply } \\
\hline & $P_{i}$ & $S_{i}^{*}$ & $\widehat{S}_{i}$ & $\widetilde{S}_{i}$ & $P_{i}$ & $S_{i}{ }^{*}$ & $\widehat{S}_{i}$ & $\widetilde{S}_{i}$ \\
\hline Benin & $11 \%$ & 49,479 & 31,300 & 20,578 & $11 \%$ & 42,379 & 17,315 & 15,755 \\
\hline Burkina Faso & $23 \%$ & 271,876 & 95,923 & 113,071 & $20 \%$ & 203,667 & 47,818 & 75,717 \\
\hline Cameroon & $9 \%$ & 101,408 & 61,716 & 42,175 & $9 \%$ & 94,852 & 38,329 & 35,263 \\
\hline Cape Verde & $34 \%$ & 6910 & 137 & 2874 & $34 \%$ & 12,505 & 231 & 4649 \\
\hline Chad & $23 \%$ & 218,190 & 36,465 & 90,743 & $23 \%$ & 180,347 & 19,201 & 67,048 \\
\hline Cote d'Ivoire & $6 \%$ & 30,755 & 25,478 & 12,791 & $3 \%$ & 35,635 & 25,487 & 13,248 \\
\hline Gambia, The & $29 \%$ & 59,007 & 4387 & 24,540 & $31 \%$ & 22,209 & 3158 & 8257 \\
\hline Ghana & $14 \%$ & 257,176 & 54,153 & 106,957 & $11 \%$ & 228,592 & 35,789 & 84,984 \\
\hline Guinea & $6 \%$ & 17,936 & 45,576 & 7460 & $6 \%$ & 10,864 & 25,322 & 4039 \\
\hline Guinea-Bissau & $17 \%$ & 14,974 & 3470 & 6227 & $14 \%$ & 14,084 & 2817 & 5236 \\
\hline Liberia & $26 \%$ & 15,564 & 3642 & 6473 & $23 \%$ & 32,455 & 4731 & 12,066 \\
\hline Mali & $11 \%$ & 110,280 & 111,866 & 45,864 & $14 \%$ & 78,210 & 52,194 & 29,076 \\
\hline Mauritania & $37 \%$ & 40,894 & 4381 & 17,007 & $17 \%$ & 66,580 & 6699 & 24,753 \\
\hline Niger & $20 \%$ & 392,751 & 93,798 & 163,341 & $20 \%$ & 345,241 & 47,663 & 128,351 \\
\hline Nigeria & $3 \%$ & 497,369 & 436,384 & 206,851 & $9 \%$ & 128,646 & 264,404 & 47,827 \\
\hline Senegal & $29 \%$ & 369,686 & 26,099 & 153,749 & $9 \%$ & 83,935 & 27,768 & 31,205 \\
\hline Sierra Leone & $23 \%$ & 77,571 & 16,413 & 32,261 & $20 \%$ & 81,657 & 10,021 & 30,358 \\
\hline Togo & $14 \%$ & 50,373 & 22,726 & 20,950 & $11 \%$ & 64,329 & 12,800 & 23,916 \\
\hline Region & $89 \%$ & $2,582,200$ & $1,074,000$ & $1,074,000$ & $89 \%$ & $1,726,187$ & 641,747 & 641,747 \\
\hline
\end{tabular}

Source: Author's computation based on USDA (2014). Note: Stock levels in mt; $P_{i}$ is the probability of intervention when production and supply are below the target consumption (99\%). $S_{i}{ }^{*}, \widehat{S}_{i}, \widetilde{S}_{i}$ are stocks without cooperation and with equal and relative contributions

Open Access This chapter is distributed under the terms of the Creative Commons AttributionNoncommercial 2.5 License (http://creativecommons.org/licenses/by-nc/2.5/) which permits any noncommercial use, distribution, and reproduction in any medium, provided the original author(s) and source are credited.

The images or other third party material in this chapter are included in the work's Creative Commons license, unless indicated otherwise in the credit line; if such material is not included in the work's Creative Commons license and the respective action is not permitted by statutory regulation, users will need to obtain permission from the license holder to duplicate, adapt or reproduce the material.

\section{References}

AFDB (2014) African Development Bank (AFDB) data portal. Available at http://www.afdb.org/ en/knowledge/statistics/data-portal/

Alesina A, Angeloni I, Etro F (2005) International unions. Am Econ Rev 95(3):602-615

Badiane O, Makombe T, Bahiigwa G (2014) Promoting agricultural trade to enhancing resilience in Africa. Annual trends and outlook report. Regional strategic analysis and knowledge support systems, Washington, DC

Cuddy JDA, Della Valle PA (1978) Measuring the instability of time series data. Oxford Bull Econ Stat 40(1):79-85 
ECOWAS Commission, UEMOA, CILSS, RESOGEST (2012) Regional food security reserve. Technical report

FAO CBS (2014) Food and Agricultural Organization Commodity Balance Sheets (FAO CBS). Provided by the Global Information and Early Warning System (GIEWS), Division of FAO

FAO, OCED, IFAD, IFPRI, IMF, UNCTAD, WFP, World Bank, WTO, UN-HLTF (2011) Price volatility in food and agricultural markets: policy responses. Technical report. FAO and OECD in collaboration with IFAD, IFPRI, IMF, UNCTAD, WFP, World Bank, WTO, and UN-HLTF on Global Food Security, Rome

FAO, IFAD, WFP (2013) The state of food insecurity in the world 2013. The multiple dimensions of food security. Food and Agriculture Organization (FAO), Rome

FAOSTAT (2014) Food and Agricultural Organization Statistics (FAOSTAT). Available at http:// faostat.fao.org/site/291/default.aspx

Gabler Wirtschaftslexikon (2014) Hodrick-prescott-filter

Gilbert CL (2011) Food reserves in developing countries: trade policy options for improved food security. Technical Report 37. International Centre for Trade and Sustainable Development (ICTSD), Geneva

Gouel C, Jean S (2015) Optimal food price stabilization in a small open developing country. World Bank Econ Rev 29(1):72-101

Gustafson RL (1958) Carryover levels for grains: a method for determining amounts that are optimal under specified conditions. Technical bulletin. United States Department of Agriculture, Washington, DC

HarvestChoice (2014) Aez (16-class, 2009). Technical report. International Food Policy Research Institute (IFPRI), Washington, DC and University of Minnesota, St. Paul, MN. Available at http://harvestchoice.org/data/aez16_code

Heinonen H (2006) Regional integration and the state: the changing nature of sovereignty in Southern Africa and Europe. PhD Thesis, University of Helsinki

Johnson D (1976) Increased stability of grain supplies in developing countries: optimal carryovers and insurance. World Dev 4(12):977-987

Koester U (1984) Regional cooperation among developing countries to improve food security. Quart J Int Agric 23(2):99-114

Koester U (1986) Regional cooperation to improve food security in southern and Eastern African countries. Research Report 53. International Food Policy Research Institute (IFPRI), Washington, DC

Konandreas P, Huddleston B, Ramangkura V (1978) Food security: an insurance approach. Research Report 4. International Food Policy Research Institute (IFPRI), Washington, DC

Kornher L (2015) Food price volatility: the role of stocks and trade. PhD Thesis, Rheinische Friedrich-Wilhelms Universität, Bonn

Lynton-Evans J (1997) Strategic grain reserves - guidelines for their establishment, management and operation. FAO Agricultural Services Bulletin 126. Food and Agriculture Organization (FAO), Rome

Makki SS, Tweeten LG, Miranda MJ (1996) Wheat storage and trade in an efficient global market. Am J Agric Econ 78(4):879-890

Makki SS, Tweeten LG, Miranda MJ (2001) Storage-trade interactions under uncertainty: implications for food security. J Policy Model 23(2):127-140

Martin W, Anderson K (2012) Export restrictions and price insulation during commodity price booms. Am J Agric Econ 94(2):422-427

Miranda MJ, Helmberger PG (1988) The effects of commodity price stabilization programs. Am Econ Rev 78(1):46-58

Newbery DMG, Stiglitz JE (1981) The theory of commodity price stabilization: a study in the economics of risk. Oxford University Press, Oxford

Porteous OC (2012) Empirical effects of short-term export bans: the case of African maize. Working Paper Berkeley, Department of Agricultural Economics, University of California

Reutlinger S, Eaton D, Bigman D (1976) Should developing nations carry grain reserves? World Bank Staff Working Paper 244, World Bank, Washington, DC 
Sarris AH, Conforti P, Prakash A (2011) The use of organized commodity markets to manage food import price instability and risk. Agric Econ 42(1):47-64

Townsend RM (1995) Consumption insurance: an evaluation of risk-bearing systems in lowincome economies. J Econ Perspect 9(3):83-102

Tschirley DL, Jayne TS (2010) Exploring the logic behind southern Africa's food crises. World Dev 38(1):76-87

USDA (2014) United States Department of Agriculture (USDA). Production, supply and distribution (PSD) online database of the foreign agricultural service. Available at http://apps.fas.usda. gov/psdonline/

von Grebmer K, Headey D, Bene C, Haddad L, Olofinbiyi T, Wiesmann D, Fritschel H, Yin S, Yohannes Y, Foley C, von Oppeln C, Iseli B (2013) 2013 Global Hunger Index: The challenge of hunger: building resilience to achieve food and nutrition security. Technical Report. Welthungerhilfe, International Food Policy Research Institute (IFPRI), and Concern Worldwide, Bonn, Washington, DC, and Dublin.

Williams JC, Wright BD (1991) Storage and commodity markets, 1st edn. Cambridge University Press, Cambridge

Wright B, Cafiero C (2011) Grain reserves and food security in the Middle East and North Africa. Food Security 3(1):61-76 